NBER WORKING PAPER SERIES

\title{
SHOULD WE TRUST CLUSTERED STANDARD ERRORS? A COMPARISON WITH RANDOMIZATION-BASED METHODS
}

\author{
Lourenço S. Paz \\ James E. West \\ Working Paper 25926 \\ http://www.nber.org/papers/w25926 \\ NATIONAL BUREAU OF ECONOMIC RESEARCH \\ 1050 Massachusetts Avenue \\ Cambridge, MA 02138 \\ June 2019
}

Thanks to our colleagues at Baylor University, Dean Karlan for authorizing the use of his lab experiments data that were published in Karlan (2005), and to the Baylor Department of Economics for the purchase of a node on the Baylor High Performance Computer Cluster. The views expressed herein are those of the authors and do not necessarily reflect the views of the National Bureau of Economic Research.

NBER working papers are circulated for discussion and comment purposes. They have not been peer-reviewed or been subject to the review by the NBER Board of Directors that accompanies official NBER publications.

(C) 2019 by Lourenço S. Paz and James E. West. All rights reserved. Short sections of text, not to exceed two paragraphs, may be quoted without explicit permission provided that full credit, including $\odot$ notice, is given to the source. 
Should We Trust Clustered Standard Errors? A Comparison with Randomization-Based Methods Lourenço S. Paz and James E. West

NBER Working Paper No. 25926

June 2019

JEL No. C18,C33

\begin{abstract}
$\underline{\text { ABSTRACT }}$
We compare the precision of critical values obtained under conventional sampling-based methods with those obtained using sample order statics computed through draws from a randomized counterfactual based on the null hypothesis. When based on a small number of draws (200), critical values in the extreme left and right tail (0.005 and 0.995) contain a small bias toward failing to reject the null hypothesis which quickly dissipates with additional draws. The precision of randomization-based critical values compares favorably with conventional sampling-based critical values when the number of draws is approximately 7 times the sample size for a basic OLS model using homoskedastic data, but considerably less in models based on clustered standard errors, or the classic Differences-in-Differences. Randomization-based methods dramatically outperform conventional methods for treatment effects in Differences-in-Differences specifications with unbalanced panels and a small number of treated groups.
\end{abstract}

Lourenço S. Paz

Department of Economics

Baylor University

One Bear Place \#98003

Waco, TX 76798

lourenco_paz@baylor.edu

James E. West

Department of Economics

Baylor University

One Bear Place \#98003

Waco, TX 76798

and NBER

j_west@baylor.edu

A data appendix is available at http://www.nber.org/data-appendix/w25926 


\section{Introduction}

In evaluating the quality of their statistical models, applied social scientists place great emphasis on the level of significance, or probability of type I error. Based upon a random sample drawn from a large (and usually unknown) population, a statement is made on the probability that the observed statistical correlation is the outcome of random sampling if the null hypothesis is correct. For sample sizes not particularly large, this exercise relies upon the asymptotic properties of estimated parameters to project critical values at customary levels of significance at which the null hypothesis would be rejected in favor of an alternate. Being the result of statistical estimation, these critical values are themselves stochastic. We illustrate

in Figure 1 an estimated parameter, $\widehat{\beta}_{2} \sim N(0,1)$ and the approximate distribution of its 0.01 critical value. The distribution of estimated critical values has not been of much interest to econometricians, as its properties are a straightforward application of the properties of the variance of the parameter estimate.

Studies using data that are natural, field, or lab experiments are fundamentally different. Variation in such studies is not the result of sampling variation, as the entire population is observed and is itself the data set. In such circumstances, the theoretical source of variation is the choice of to whom the treatment is applied. Athey and Imbens (2017) argue that randomization based inference is more appropriate to the design of such experiments than conventional sampling-based inference. In addition, randomization-based inference can be useful in situations with few observations available (such as historical data), or in an experimental lab context where it is time consuming, expensive, or infeasible to collect additional data.

Randomization based inference utilizes randomly generated counterfactuals to obtain an empirical distribution of estimated parameters under the null hypothesis. As an example, Karlan (2005), whose experiment we discuss in section 4, implements a trust game in a lab setting. To distinguish systematic choices from random play, in the counterfactual we 
replace the actual choices made by players with randomly chosen outcomes. After performing a number of draws, we compare model parameters estimated using actual choices with the distribution of parameters using generated counterfactual data. This is distinct from a randomized control trial, where a control group is denied treatment and presumed to follow random behavior.

A growing number of papers based on natural, field, or lab experiments are using randomizationbased methods. ${ }^{1}$ In the papers of which we are aware, authors have not employed systematic methods to determine the appropriate number of randomized counterfactual draws to perform in which to achieve acceptably accurate type I error estimates and reasonable statistical power. This exercise is of fundamental importance because the process of drawing randomized conterfactuals can require substantial computing resources for large datasets such as matched employer-employee data or retail scanner data.

In this paper, we compare the performance of conventional inference-based statistical methods with that of randomization-based methods. In symmetric distributions, we examine type I statistical error at the 0.05, 0.025, and 0.005 level as well as statistical power in a variety of commonly encountered frameworks in which the statistical properties of Ordinary Least Squares (OLS) estimated parameters are not desirable, up to and including difference-in-difference models with unbalanced panels, a small number of clustering units, heteroscedasticity by cluster, and treatment in as little as one cluster.

Even under the most difficult assumptions, we find that randomization-based inference methods compare favorably to conventional inference-based methods. In cases with as few as one treated group where inference-based methods are severely biased toward over-rejecting the null hypothesis of no treatment effect, randomization-based methods continue to exhibit

\footnotetext{
${ }^{1}$ Recent examples employing this technique include papers where students are assigned to peer groups, (Carrell, Sacerdote, and West, 2013) classrooms, (Lim and Meer, 2017) and career mentors, (Kofoed and McGovney, 2017), and the matching of college roommates within a dorm (Carrell, Hoekstra, and West, 2018). These methods can be used to construct appropriate counterfactuals, even when the entire population is not observed. (Chetty, Looney, and Kroft, 2009)
} 
a slight under-rejection of the null hypothesis using 200 draws which corrects with a larger number of draws. In cases with more treated groups, the severe bias of OLS toward overrejection of the null lessens. We find power using randomization-based methods to be less than with inference-based methods, but attribute some of this to the over-rejection of the null hypothesis by conventional methods. For models estimated using larger data sets, we propose that the number of draws be a multiple of 200 , but not less than $7 G$, where $G$ is the number of cluster groups. We also compare the accuracy and power of conventional sampling-based methods with randomization-based methods when the number of draws greatly exceeds $7 G$. We find that accuracy improves rapidly as the number of draws increases beyond $7 G$, but at a diminishing rate.

The techniques we investigate have some similarities but are distinct from a percentile- $t$ bootstrap and a wild-cluster bootstrap. A percentile-t bootstrap computes estimated parameters on data resampled at the cluster level with replacement as an intermediate step in the resampling process. Cameron, Gelbach, and Miller (2008) find that a percentile- $t$ bootstrap is subject to over-rejection and proposed the wild-cluster bootstrap, in which weights of -1 or 1 are randomly assigned to clusters. In contrast, the methods we investigate involve the generation of a number of counterfactuals, in which the treatment status is varied at the individual observation level.

In the remainder of this paper, section two describes the statistical methods employed in our analysis. Section three presents and discusses the results of our Monte Carlo simulations. Section four presents the application of our methodology to Karlan (2005). The last section concludes. 


\section{Statistical Methods}

Let the entire population or census of an outcome of interest $Y_{n \times 1}$ be a linear function of a nonstochastic matrix of variables $X_{n \times k}$ with a first column of 1's.

$$
Y=X \beta+\varepsilon
$$

Equation (1) is assumed to be correctly specified with a stochastic error function

$$
\varepsilon \sim \operatorname{IID}\left(0, \sigma^{2} I_{n}\right)
$$

Under these conditions, the Ordinary Least Squares estimate

$$
\widehat{\beta} \underset{n \rightarrow \infty}{\longrightarrow} N\left(\beta, \sigma^{2}\left(X^{\prime} X\right)^{-1}\right)
$$

and the OLS estimate of $\sigma^{2}$ is

$$
S^{2}=\frac{(Y-X \widehat{\beta})^{\prime}(Y-X \widehat{\beta})}{n-k} \sim\left(\sigma^{2}, \frac{2 \sigma^{4}}{n}\right) .
$$

Using conventional sampling-based inference methods, a one-tailed confidence interval at an $\alpha$ level of significance for $\beta_{i}$ can be constructed around a hypothesized value, $\beta_{i, 0}$, as

$$
\beta_{i, 0}-t_{\alpha, d f} S_{\widehat{\beta}_{i}}
$$

In a correctly specified model where $\mathbb{E}\left(S^{2}\right)=\sigma^{2}$ and under the null hypothesis, the probability that $\beta_{i}$ is strictly less than Equation (2) is $\alpha$. 
The variance of the critical value of the one-tailed confidence interval is

$$
\begin{aligned}
V\left(\beta_{i,(0)}-t_{\alpha, d f} S_{\widehat{\beta}_{i}}\right) & =\left(t_{\alpha, d f}\right)^{2} V\left(S_{\widehat{\beta}_{i}}\right) \\
& =\left(t_{\alpha, d f}\right)^{2}\left(X^{\prime} X\right)_{i, i}^{-1} \frac{2 \sigma^{2}}{n-k}\left[\frac{n-k}{2}-\frac{\Gamma^{2}\left(\frac{n-k+1}{2}\right)}{\Gamma^{2}\left(\frac{n-k}{2}\right)}\right]
\end{aligned}
$$

since

$$
\frac{\sqrt{n-k}}{\sigma} \cdot S \sim \chi_{n-k}\left(\sqrt{2}\left[\frac{\Gamma\left(\frac{n-k+1}{2}\right)}{\Gamma\left(\frac{n-k}{2}\right)}\right], 2\left[\frac{n-k}{2}-\frac{\Gamma^{2}\left(\frac{n-k+1}{2}\right)}{\Gamma^{2}\left(\frac{n-k}{2}\right)}\right]\right)
$$

Using $d$ draws of $\widehat{\beta}_{i}$ under an appropriately constructed counterfactual, the resulting $\widehat{\beta}_{i,(1)}, \ldots, \widehat{\beta}_{i,(d)}$ would be IID with a cumulative distribution function (CDF) F. Assume that $F$ has a density $f$ that is positive and continuous for every $F^{-1}(q)$, where $q$ is the $q^{\text {th }}$ sample quantile, $0<q<1$. For a sufficiently large $d$, the $q^{\text {th }}$ sample quantile is approximately normally distributed (Ruppert and Matteson (2015)) with mean equal to the population quantile $F^{-1}(q)$ and variance equal to:

$$
V(q)=\frac{q(1-q)}{d\left[f\left(F^{-1}(q)\right)\right]^{2}}
$$

We report in Table 1 the mean and standard deviation of order statistics from a standard normal distribution which can be used to estimate a $\alpha=0.005,0.025$, and 0.05 critical value. To estimate a 0.005 critical value, multiples of 200 draws are required. With the minimum 200 draws, the expected value of first order statistic at -2.7460 is approximately 0.2 standard deviations less than $\Phi(0.005)=-2.5758 .{ }^{2}$ As a consequence of this bias, type I error from randomization-based inference using 200 draws will be too small and type II error elevated. As the number of draws is increases and the estimator of the 0.005 critical value is that of higher order statistics, both the bias and the dispersion of the estimator (as measured by the standard deviation) rapidly decreases. In a sample of 10,000 draws, the bias of $50^{\text {th }}$ order

\footnotetext{
${ }^{2}$ This bias of the first order statistic in small samples as an estimator of population quantiles is well documented in the literature. For further detail, see (Petzold, 2000).
} 
statistic as an estimator of $\Phi^{-1}(0.005)$ is 0.0031 . The increased precision associated with higher value order statistics can also be seen in comparing the estimates of the 0.005 critical values with 0.025 and 0.05 values. Estimates of the 0.025 critical value based on the fifth order statistic from 200 draws has both bias and standard errors roughly comparable to the fifth order statistic of 1,000 draws, which is used to estimate the 0.005 critical value.

To more directly compare the precision of inference-based critical values with those obtained by randomization-based methods, we set Equations (4) and (5) equal, and solve for the number of randomized draws $d$ to equate the variance of randomization and inference-based methods for selected sample sizes $n$. We note that the number of draws is approximately seven times the sample size to equate the variance of the 0.005 confidence interval obtained under randomization and sampling-based inference, or $d \approx 7 n$.

For regressions based on homoskedastic data, we conclude that the dispersion of 0.005 critical values obtained using randomization-based methods is roughly similar to those obtained using conventional sampling-based methods when the number of draws is approximately seven times the sample size. To obtain two-tailed critical values at a one-percent level, the number of draws must be multiples of 200. Critical values based on 200 draws will be biased toward under-rejection of the null hypothesis, however this bias declines rapidly in draws of higher multiples of 200.

\subsection{Clustered Data}

Empirical economists frequently encounter panel data which is homoskedastic within each cross-sectional group $g$, but potentially heteroskedastic across groups $(g=1, \ldots, G)$ of an unspecified form. For a balanced panel, containing an equal number of observations in each 
cross sectional group, $N$, the variance of the error term is

$$
V\left[\begin{array}{c}
\varepsilon_{1,1} \\
\vdots \\
\vdots \\
\varepsilon_{N, G}
\end{array}\right]=\left[\begin{array}{cccc}
\sigma_{1}^{2} & 0 & \ldots & 0 \\
0 & \sigma_{2}^{2} & & \vdots \\
\vdots & & \ddots & \\
0 & \ldots & 0 & \sigma_{G}^{2}
\end{array}\right] \otimes I_{N}
$$

Under these circumstances, the estimated variance of the OLS estimator computed with clustered standard errors is

$$
\widehat{V}\left(\widehat{\beta}_{O L S}\right)=\left(X^{\prime} X\right)^{-1} X^{\prime}\left(\left[\begin{array}{cccc}
S_{1}^{2} & 0 & \ldots & 0 \\
0 & S_{2}^{2} & & \vdots \\
\vdots & & \ddots & \\
0 & \ldots & 0 & S_{G}^{2}
\end{array}\right] \otimes I_{N}\right) X\left(X^{\prime} X\right)^{-1}
$$

To derive results comparable to Table 2, where (6) is set equal to (5) for various $d$ and $N$ would require assumptions on $X$ and $S_{i}^{2}$. Instead, we compare the distributions of (6) and (5) for both balanced and unbalanced cluster sizes using Monte Carlo methods in the following section.

\section{Monte Carlo Methods}

To investigate the distributions of confidence intervals under a variety of statistical distributions, we begin with a set of 100,000 p-values distributed uniformly [0,1]. Using these $p$-values, we generate realizations of the generalized Lambda distribution that has the following inverse CDF. (Ramberg, Dudewicz, Tadikamalla, and Mykytka, 1979)

$$
F^{-1}(p)=\mu+\sigma\left[p^{a}-(1-p)^{b}\right]
$$


The generalized lambda distribution with appropriate choices of $a$ and $b$ can resemble lighttailed, medium-tailed, heavy-tailed, normal-like, and exponential distributions. (Harrell and Davis, 1982) Table 3 shows the values of $a$ and $b$ used to generate samples of these distributions. Summary statistics of the generated samples are also reported in Table 3, and their histograms are exhibited in Figure A.1. We set the mean adjustment parameter $\mu$ to 0 and the scale parameter $\sigma$ to 1 for the initial homoskedastic cases. We also generate a spurious explanatory variable, $X_{i} \sim N I D(0,1)$.

Using these variations of the generalized lambda distribution and $X_{i}$, we compute the probability of Type I error and statistical power for three separate Monte Carlo designs; the simple regression slope in a linear model with a homoskedastic error term, the regression slope in a linear model with clustered standard errors, and the treatment effect in a linear difference-in-differences model with clustered standard errors. We further consider both balanced and unbalanced panels within the clustered and the difference-in-difference cases.

\subsection{Homoskedastic Case}

We first consider a simple example in which to compare sampling and randomization-based inference methods using homoskedastic data with 40 observations. Based on results presented in Table 2, the variance of 0.005 level type I critical values (-2.712 standard deviations) should be comparable between sampling and randomization based methods. Further, it is of interest how randomization-based methods perform in a scenario where conventional sampling based methods are understood to have desirable statistical properties.

Using Equation (7), we generate $\varepsilon_{i}$ for each of the five distributions detailed in Table 3. We draw one million samples of 40 observations without replacement from the population of 100,000 and compute

$$
Y_{i}=\beta_{1}+\beta_{2} X_{i}+\varepsilon_{i},
$$


for $\beta_{1}=\beta_{2}=0$. Using this data, we estimate

$$
Y_{i}=\widehat{\beta}_{1}+\widehat{\beta}_{2} X_{i}+\widehat{\varepsilon}_{i}
$$

using OLS. To compare type I error under sampling and randomization based inference methods, we construct empirical distributions of the standardized $\alpha \times 100$ critical value under a null hypothesis of $\beta_{2}=0$. Under the null hypothesis and the asymptotic normality of $\widehat{\beta}_{2}$, with a sample size of 40 observations,

$$
\frac{\widehat{\beta}_{2}}{s_{\widehat{\beta}_{2}}} \sim t_{38}
$$

Sampling based methods project that under the null hypothesis, $\alpha$-percent of $\widehat{\beta}_{2}$ are expected to be strictly less than

$$
t_{38, \alpha} \cdot s_{\widehat{\beta}_{2}}
$$

where

$$
s_{\widehat{\beta}_{2}}=\frac{\frac{1}{38} \sum_{i} \widehat{\varepsilon}_{i}^{2}}{\sum_{i}\left(X_{i}-\bar{X}\right)^{2}} .
$$

To construct a randomization-based analog to Equation (10), we compute the appropriate sample order statistic from a random draw of $d$ observations from $\widehat{\beta}_{2}$ standardized with the sample mean and standard deviation from the entire sample of 1 million values computed. If 200 draws are performed, the 0.005 sample quantile is the first order statistic. If $d$ draws are performed, the $\alpha$ sample quantile is estimated by the $d \alpha$ order statistic.

$$
\begin{aligned}
& t_{s}=t_{38, \alpha} \cdot \frac{s_{\widehat{\beta}_{2}}}{\sigma_{\widehat{\beta}_{2}}}, \\
& t_{r}=\left(\frac{\widehat{\beta}_{2}-\mu_{\widehat{\beta}_{2}}}{\sigma_{\widehat{\beta}_{2}}}\right)_{(d \alpha)},
\end{aligned}
$$


$t_{s}$ and $t_{r}$ can be directly compared as the critical value measured in standard deviations from mean at an $\alpha$ level of significance for sampling and randomization-based inference respectively. They can also be compared to the theoretical critical value of $t_{38, \alpha}$ under the asymptotic normality of $\widehat{\beta}_{2}$.

Table 4 reports summary statistics of simulations based on 1 million replications of sample size 40 drawn from a homoskedastic normal-like, light, medium, and heavy-tailed distribution. For the symmetric distributions of Table 4, we evaluate only the left tail. And for the asymmetric exponential-like distribution, we evaluate right and left tails separately, which are reported in Table 5.

For each distribution, we present the mean of 1 million computations of $t_{s}$ and 100,000 computations of $t_{r}$ based on 200,400,1,000, and 5,000 draws without replacement from the standardized $\widehat{\beta}_{2}$. For each set of draws, we compute the 0.005, 0.025, and 0.05 sample quantile. Additionally, for the non-symmetric exponential-like distribution in Table 5, we also compute the $0.95,0.975$, and 0.995 sample quantiles.

Panel A contains information for the left-tail quantiles and Panel B for the ones in the right tail. We report the sample means and standard deviations of sampling-based $t_{s}$ in columns 1,3 , and 5 , and the sample means and standard deviations of randomization-based $t_{r}$ in columns 2,4 , and 6 . At the bottom of each block, we report a $p$-value in square brackets, representing the proportion of $t$ statistics that are less than the respective theoretical critical value as given in the column heading. For randomization-based columns $(2,4$, and 6$)$, these are equal to the theoretical significance levels $0.05,0.025$, and 0.005 by construction.

A-priori, we expect results from sampling-based methods to closely conform to theoretical predictions in the homoskedastic cases. A sample size of 40 is sufficiently large so that $\widehat{\beta}_{2}$, being a weighted average of the supporting $\varepsilon_{i}$, approaches a normal distribution by the central limit theorem in these ideal cases. Because of this, $t_{s}$ and $t_{r}$ will be distributed $t_{38}$. We report the mean and standard deviations of relevant order statistics in Table 1 for 
a standard normal distribution. In appendix table $A$.1, we report the mean and standard deviation of relevant order statistics for draws from a $t_{38}$ distribution. Due to the heavier tails of a $t_{38}$ versus a standard normal, both the reported bias and standard deviation are larger relative to $t_{38, \alpha}$, particularly for $\alpha=0.005$ and $d=200$. The statistics we report in Tables 4 and 5 are consistent with these expectations. The sampling-based inference average $t_{s}$ is closer to the theoretical $t_{38, \alpha}$ than that obtained via randomization, albeit this difference is approximately 2 percent. Notice that conventional inference tends to over-reject the null hypothesis for the normal and light-tailed distributions. As expected, the performance of randomization-based methods declines in the more extreme quantiles of 0.005 , with the exception of the medium- and heavy-tailed distributions. As a consequence of the variance of $t_{r}$ being inversely proportional to the number of draws, $d$ (see Equation (5)), the standard deviation of $t_{r}$ declines uniformly for 400, 1,000, and 5,000 draws from 200 draws.

In Figure 2, we present histograms of the empirical distributions of $t_{s}$ (dashed line) and $t_{r}$ with 200 draws (solid line) at a 0.005 level of significance as shown in columns (5) and (6) of Table 4 for each distribution of interest. The vertical bar in each panel of Figure 2 is $t_{38,0.005}=-2.7116$, the theoretically correct critical value under the assumption that $\widehat{\beta}_{2}$ is asymptotically normal. Figure 3 contains results from the right and left tails of the exponential-like distribution. In the first row of Figure 3 which presents results from the left tail, the vertical line is $t_{38,0.005}=-2.7116$ as in Figure 2. The second row of Figure 3 presents results from the right tail, where the vertical line is $t_{38,0.995}=2.7116$. Results from Table 4 indicate that the mean of the sampling-based methods, $t_{s}$, is closer to the theoretically correct value of -2.7116 than that of the randomization-based methods, $t_{r}$. In contrast, the mode of $t_{r}$ is closer to the theoretically correct vertical line in each panel than the mode of $t_{s}$. This is particularly true in Figure 3 for both the left and right tails of the exponential-like distribution. Computations presented in Table 2 indicate that the standard deviations of $t_{s}$ and $t_{r}$ should be very close for 200 draws. The standard deviations reported 
in the first columns of Figures 2 and 3 largely conform to this expectation. For higher number of draws, $t_{r}$ has a smaller dispersion than that of $t_{s}$. As expected, the performance of randomization-based methods is considerably better for the heavy-tailed distribution and for the (asymmetric) exponential distribution.

To evaluate statistical power, we generate $Y_{i}$ as specified in equation (8) with an alternative hypothesis of $\beta_{2}=0.1$. By construction we are expecting the power of this test to be low due to the small magnitude of $\beta_{2}$ relative to the constructed variation of $X$. For the samplingbased inference results, we compute a conventional $t$-statistic on a null hypothesis that $\beta_{2}=0$ against an alternate that $\beta_{2} \neq 0$. The power level of these tests are reported in Table 6 , in columns (1), (3), and (5) labeled "sampling, " where we report the proportion of 1,000,000 $t$-statistics for which $t<t_{38, \alpha / 2}$ or $t>t_{38,1-\alpha / 2}$. For the randomization-based methods, we determine whether $\widehat{\beta}_{2}$ estimated using data generated with $\beta_{2}=0.1$ (alternate hypothesis) is less than the $\alpha / 2$ sample quantile or greater than the $1-\alpha / 2$ sample quantile from 200 , $400,1,000$, or 5,000 draws of counterfactual $\widehat{\beta}_{2}$ constructed with $\beta_{2}=0$. The power level of these tests are reported in columns (2), (4), and (6) of Table 6. The randomization-based test has higher power in all cases, even in the case of the extreme quantiles $(\alpha=0.01)$. Such a difference in performance is large for the light- and heavy-tailed distributions, though it is small for the medium-tailed and exponential distributions. We can also see that the figures indicate that the light-tailed and the heavy-tailed distributions are the extreme cases. Thus, the next simulations will employ only these two distributions. Overall, the randomizationbased method performs as well as and in some cases better than conventional sampling-based methods in conditions under which the latter methods are expected to perform particularly well. 


\subsection{Clustered Case}

We consider two different numbers of clustered groups: 12 and 50. The first represents a very small number of groups like Canadian provinces and territories, while the other case corresponds to the number of American states. The findings from (Cameron, Gelbach, and Miller, 2008) indicate that conventional-based inference will perform well in the case of 50 clusters and poorly in the case of 12 clusters. To generate clustered random variables, from the previously defined 100,000 uniformly distributed $p$-values [0,1], we set the scaling parameter for each clustered group in the generalized lambda distribution (Equation (7)) to be drawn $\sigma_{g} \sim U[0.5,1,5]$. We also apply this scaling to the spurious explanatory variable $X_{i}, X_{g i}=\sigma_{g} X_{i}$. We randomly choose $N=40$ observations from each clustered group of both the dependent variable and the stochastic disturbance and compute

$$
Y_{g i}=\beta_{1 g}+\beta_{2} X_{g i}+\varepsilon_{g i}
$$

for $\beta_{1 g}=\beta_{2}=0 .^{3}$ For each number of clustered groups, $g=1 \ldots 12$ and $g=1 \ldots 50$, we repeat 1,000,000 times for $\varepsilon_{g i}$ chosen from the heavy-tailed and light-tailed distributions. We estimate parameters using panel OLS with fixed effects with clustered standard errors. Sampling-based and randomization-based statistics are implemented as in the homoskedastic case.

We present Type I error results in Table 7 for the case of 12 and 50 balanced clusters. Panel A presents results when the stochastic disturbance is drawn from a light-tailed distribution, and Panel B when the stochastic disturbance is drawn from a heavy-tailed distribution. For the 12-cluster case the randomization-based inference performs better for both the light- and heavy-tailed distributions even for the most extreme quantile $\alpha=0.005$ with only 200 draws. In the 50-cluster case, the performance of both methods is almost identical with a small advantage for the randomization method. The sampling-based method tends

\footnotetext{
${ }^{3}$ As in Cameron, Gelbach, and Miller (2008).
} 
to over-reject the null hypothesis, which is very pronounced in the 12-cluster case. In the 50 -cluster case at the 0.005 level, $t_{r}$ exceeds the theoretical critical value $t_{1949,0.005}$ for 200 draws in both the light and heavy-tailed cases. When computed with 400 and especially 1,000 draws, $t_{r}$ much more closely approximates its theoretical value.

In Figures A.2 and A.3, we show the distributions of the sampling- and randomizationbased $t_{s}$ and $t_{r}$ for $\alpha=0.005$ for the heavy-tailed and light-tailed distribution (respectively), and as the number of draws $d$ increases (horizontal axis) and the number of cluster units $G$ grows (vertical axis). We note first that as the number of draws is increased (left to right panels within line of Figures A.2 and A.3), the variance from randomization-based methods decreases. This result is to be expected from (5). And as the number of cluster units $G$ increases from 12 to 50 (top to bottom panels within columns of Figures A.2 and A.3), the variance of randomization-based methods is largely unaffected. With a small number of clusters, critical values estimated by OLS with clustered standard errors are known to be downward-biased. (Cameron and Miller, 2015) This can be observed in the first rows of Figures A.2 and A.3 with $G=12$. We note that randomization-based methods perform considerably better in our simulations. For all distributions of dependent variables, we note that the variance of randomization and sampling-based methods is roughly comparable for $G=50$ and $d=200$, as seen in the bottom left panel $(i)$ in each of Figures A.2 and A.3. Based on the variations shown in Figures A.2 and A.3, the variation of 0.005 critical values obtained by randomization-based methods is no more than that obtained by inference-based methods if $d \geq 7 G$ but not less than 200 .

To evaluate statistical power, we compute equation (13) for $\beta_{2}=0.025$, which is the alternate hypothesis. Sampling-based and randomization-based statistics are again developed as in the homoskedastic case. Analogous to Table 6, we report the proportion of the 1,000,000 t-statistics computed with clustered standard errors that reject the null hypothesis of $\beta_{2}=0$ in favor of a two-tailed alternate at the indicated level of significance in columns 
(1), (3), and (5) of Table 6. Results in columns (2), (4), and (6) of Table 8 are computed exactly as in Table 6 . These results indicate that the power of randomization-based inference is smaller for more extreme quantiles, as expected. Additionally, increasing the number of draws improves the statistical power for the randomization-based method, though the increase in power is larger for the extreme quantiles. Overall, the power is close to that of sampling-based methods, and randomization-based methods do not exhibit a substantial over-rejection of the null hypothesis as do sampling based methods, especially for the case of a small number of clusters.

\subsection{Difference-in-Differences case}

Building in complexity off the previous clustered case, we consider a classic difference-indifferences (DiD) model with a small number of treated states. This is another model in which OLS is known to perform particularly poorly. (Conley and Taber, 2011) As in the clustered case, we consider the number of groups (or states) to be either 12 or 50, and the number of treated states 1,5 , or 10 . Constructing $X_{g i}$ and $\varepsilon_{g i}$ as before, we compute

$$
Y_{g i}=\beta_{1 g}+\beta_{2} X_{g i}+\beta_{3} T_{g i}+\varepsilon_{g i}
$$

for $\beta_{1 g}=0, \beta_{2}=0.5$, and $\beta_{3}=0$. We choose the state(s) to receive treatment at random, and for each treated state, a total of $U[10,30]$ units out of 40 receive treatment. We set $T_{g i}=1$ for a treated state and $T_{g i}=0$ for an untreated state. Then, we estimate parameters using panel OLS with fixed effects and standard errors clustered at the appropriate level.

Type I errors for the treatment effect $\widehat{\beta}_{3}$ are presented in Table 9 for the case of 12 clusters. Here the type I errors estimated using randomization-based methods are considerably more accurate than those for the sampling-based methods. In the case of one treated unit, the type I error is dramatically large for the sampling-based methods-our simulations (erroneously) 
found effects significant at a 0.5 -percent level in over 45 percent of replications for the case of 1 treated state (square brackets of odd-numbered columns). This is a well-known weakness of OLS DiD estimators. (Conley and Taber, 2011) The absolute deviation of $t_{r}$ from its theoretical critical value declines as the number of draws increases for each variation of number of treated states. The performance of sampling-based inference dramatically improves as the number of treated states increases. Yet, even after such an improvement, this method still over-rejects the null hypothesis at $\alpha=0.05,0.025$, and 0.005 . Overall, the null hypothesis of no effect is incorrectly rejected much more frequently for sampling-based methods $\left(t_{s}<t_{\alpha, \text { d.f. }}\right)$ than for randomization-based methods $\left(t_{r}<t_{\alpha, d . f .}\right)$.

To evaluate statistical power as in the clustered case, we employ equation (14) with $\beta_{3}=0.1$ as the alternate hypothesis. The results appear in Table 10. For the case of one treated unit, we have an abnormally high statistical power of sampling-based inference tests that we attribute to the same weaknesses that led to over-rejection of the null hypothesis when true. This is corroborated by the fact that the power declines when the number of treated states go from 1 to 5 and then it increases for ten treated units. The power statistics for randomization-based inference tests follow the same pattern of Table 8. The power is increasing in the number of draws, and is smaller for the more extreme quantiles. Consistent with our previous results, power for the heavy-tailed distribution is greater than for the lighttailed distribution. New to the DiD case is that as the number of treated units increases, the power of randomized methods increases monotonically.

The results for the Type I error for the case of panel difference-in-differences with 50 clusters are in Table 11. We observe similar patterns to that of Table 9 - in particular, over-rejection of the null hypothesis in general for sampling-based methods, which becomes dramatic when the number of treated states is small. Relative to Table 9 , a larger number of clusters improves the performance of the randomization-based inference marginally for the case of one treated unit while the performance for five and ten treated units is similar to that 
observed in Table 9. The evaluation of these tests' statistical power when $G=50$ is reported in Table 12. We can see that the same patterns of Table 10 appear here too. As expected, sampling-based inference performs very poorly in the case of few treated states, and the randomization-based inference provided robust results even in the case of one treated state. The analysis now turns to the case of unbalanced panels in the next subsection.

\subsection{Unbalanced Panels}

Finally, we consider our clustered and panel difference-in-differences specifications using unbalanced panels. For the case of 12 clustered units, we weight observations per group in proportion to the population of Canadian provinces as reported by the 2016 Census. We assign the least populous group (Northwest Territories) five observations, and weight in proportion up through the largest (Ontario) receiving 3,360 observations for a grand total of 8,750 observations. Similarly, for the 50 clustered unit case, we weight according to the population of U.S. States as given by the 2010 Census. We again assign the least populous group (Wyoming) five observations. The number of observations increases through the largest state (California), which receives 372 observations for a grand total of 3,057 observations. ${ }^{4}$ An important implication of the larger sample size used in the unbalanced variations is that the standard errors of parameter estimates are substantially smaller than those observed when using the smaller balanced data set for both the clustered and DiD cases. ${ }^{5}$ In order to make power analysis statistics more comparable between balanced panel and unbalanced cases, we reduce the magnitude of the treatment effect for the unbalanced cases to maintain parity between the standard error of parameter estimates and the treatment effect.

\footnotetext{
${ }^{4}$ For the DiD specifications where treated states must have both treated and untreated observations, observations less than 5 encounter issues of micronumerosity.

${ }^{5}$ Even if the number of observations were equal in both the balanced and unbalanced cases, $N G=$ $\sum_{g \in G} N_{g}$, the standard errors of the estimated parameters need not have a similar magnitude because of the heteroscedasticity across cluster groups.
} 
Table 13 reports type I error statistics for the unbalanced cluster case for the light-tailed distribution in columns (1) through (6) and for the heavy-tailed distribution in columns (7) through (12). Relative to the balanced panel results presented in Table 7, the over-rejection of the null hypothesis by sampling-based methods becomes more pronounced using unbalanced panels. This is expected since Conley and Taber (2011) also note this increased over-rejection of the null in unbalanced panels. The type I error statistics for the randomization-based method show a pattern similar to that presented in Table 7.

In Panels $\mathrm{A}$ and $\mathrm{B}$ of Table 14, we can see the power analysis for the light-tailed and heavy-tailed distributions respectively. The alternative hypothesis for the 12-cluster case is 0.004 and for the 50 -cluster case is 0.017 . The results in Table 14 resemble those of the clustered case in Table 8. As before, we observe a higher power in the case of the heavy-tailed distribution, and the power falls for the more extreme quantiles. A larger number of draws leads to a modest increase in power. The sampling-based inference is expected to perform well when the number of clusters is 50, though in this case its power is slightly inferior to that of the randomization-based method.

Moving to the difference-in-difference specifications, Table 15 shows the results of the Type I error for the case with 12 unbalanced clusters. Columns (1) through (6) are for the light-tailed distribution and columns (7) through (12) for the heavy tailed distribution. The patterns that emerge from this table are comparable to those observed with balanced panels in Table 9, albeit a few features merit further discussion. Sampling-based methods exhibit an even greater over-rejection of the null hypothesis for all cases. The results for the randomization-based methods indicate that the accuracy of $t_{r}$ improves substantially as the number of draws increases relative to those in Table 9. In summary, for randomization-based inference, the accuracy of type I errors is largely unaffected by the additional complication of an unbalanced panel, though the accuracy of type I errors using sampling-based methods further deteriorates. 
Regarding the power analysis of these iterations, the alternative hypothesis is a coefficient value of 0.011 for the 12 -cluster case. The power analysis figures in Table 16 show a similar picture to that of Table 14. The power is higher for the heavy-tailed distribution (Panel B) relative to that of the light-tailed distribution (Panel A). The power is smaller for the more extreme quantiles. And the (small) improvement in power obtained by increasing the number of draws is declining in the number of treated states and in the more extreme quantiles.

Table 17 depicts the results of the Type I error for the case of DiD with 50 unbalanced clusters. The sampling-based method shows greater over-rejection of the null relative to the levels of Table 11 in practically all cases. The results for the randomization-based methods exhibit a comparable performance to that of the balanced clusters in Table 11 . And the $t_{r}$ figures in Table 17 are similar and slightly closer to the theoretical critical value relative to the figures in Table 15 for the unbalanced 12-cluster case. In particular, the accuracy of type I errors also modestly improves as the number of draws increases from 200 to 5,000.

Table 18 shows the results of the power analysis of the 50 clustered unit unbalanced panel case. The alternative hypothesis for the 50-cluster case is a coefficient value of 0.1 . We can see that the power of sampling-based inference improves relative to that of the balanced cluster case reported in Table 12. This is not unexpected given the increase in type I error observed in Table 17. For the randomization-based methods, the results for the light-tailed distribution indicate a lower power for the case of one treated stated relative to those reported in Table 16. And this decline is larger for $\alpha=0.01$. Nonetheless, the power is at least 80 percent larger for five and ten treated states. In contrast, the power for the heavy-tailed distribution (Panel B) is always larger by at least fifty percent than that reported in Table 16. As in Tables 12 and 16, the power increases with the number of treated states and the number of draws. Note that the largest gains in power due to the increase in the number of draws take place in the case of one treated state. Overall, both methods are adversely affected by unbalanced panels, but the adverse effect is much more pronounced in 
the sampling-based methods.

\subsection{Summary of Monte Carlo Results}

We have conducted a series of Monte Carlo simulations to compare the precision and power of sampling- and randomization-based methods both in the simple case where theoretical results were tractable and for cases more frequently encountered by applied microeconomists that are not mathematically tractable. Theoretical calculations indicate that for homoskedastic data, the variance of a 1-percent critical value should be roughly equivalent if the number of randomized draws, $d$, is 7 times as large as the sample size, $n$. We compare the variance of a sampling-based $0.005 t$-statistic in a sample of 40 observations with the variance of its randomization-based analog, the first sample order statistic from 200 draws, which is the minimum number of draws to implement a two-sided test at a 0.01 level of significance. For all distributions considered, we find the variance of randomization-based critical values to be comparable and all slightly smaller. These results are consistent with our suggested rule for homoskedastic data sets that $d \geq 7 n$.

For the more complex slope estimated using fixed effects with clustered standard errors, we find randomization-based inference to outperform sampling-based inference with as few as 200 draws and to perform even better as $d$ is increased. The improvement in performance is particularly dramatic when the number of clustered groups is small, where OLS with clustered standard errors is known to perform poorly. For this type of inference, we recommend $d \geq 7 G$, but no fewer than 200 draws.

We also examine the properties of inference of the estimated treatment effect in a panel difference-in-differences framework. In cases with one treated group, where OLS with clustered standard errors is known to greatly overreport Type I error, randomization-based inference performs very well by comparison with as few as 200 draws, further improving with additional draws. We are confident of comparable accuracy when $d \geq 7 G$. By com- 
parison, OLS with clustered standard errors found a treated effect at a 0.005 level of significance in around $50 \%$ of repetitions when by construction none existed. In these models, randomization-based methods did exhibit reasonable statistical power.

Finally, we consider both clustered and DiD specifications with unbalanced panels. The contrast between the performance of OLS with clustered standard errors and randomizationbased methods grew. Most important, our simulations show that randomization-based inference is robust to the cases in which sampling-based inference performs poorly, namely unbalanced cluster size, small number of clusters, and few treated units. This highlights the importance and usefulness of randomization-based inference.

\section{An Application}

To illustrate the use of randomization-based methods in a published study with available data, we reconsider results from Karlan (2005). This paper links the results of two lab experiments made with participants of a Peruvian microcredit program to the observed savings and loan repayment behavior of the same participants. This paper has a well-designed lab experiment that is in line with the best practice recommendations by Athey and Imbens (2017). Its data is publicly available, and it has an easy to understand counterfactual that can be computed in a straightforward manner. The data is clustered on 41 groups. Using 400 draws, we expect to find largely similar results on the basis of our Monte Carlo analysis. In sum, it is a comprehensive paper and a straightforward example of how to apply randomization-based methods.

We will focus on the estimates involving the two lab experiments' results that are reported in Karlan's (2005) Table 3. The first experiment is the Trust Game (Barr, 2003). Participants of this game are randomly paired. They are designated different roles (either A or B). There is no communication among players. Type A players receive three coins. They then decide to pass $0,1,2$, or 3 coins to their assigned type B player. The administrator matches the 
amount passed by player A, so player B effectively receives two times the amount passed by player A. Next, player B chooses to return to player A any number of the received coins. The subgame perfect equilibrium of this finite game is to have B returning zero coins and A passing zero coins.

The counterfactual generated for this game is based upon random draws from a discrete uniform distribution. It consists of randomly generating the amount of coins passed by player A for columns 1, 3, and 4 of Karlan's (2005) Table 3. The counterfactual for the number of coins returned by player B-columns 2 and 5-is also a random draw from a discrete uniform distribution where the largest number of coins that can be returned is two times the actual number of coins passed by player A. The randomized based inference are reported in our Table 19 and it is conducted with 400 draws, which is the nearest 200 multiple of seven times the number of clusters (41 in Karlan's paper). This table reports the original significance levels indicated by $*$ as well the randomization-based $p$-values in brackets and significance levels indicated by + .

Contrasting the original and the randomization-generated $p$-values in columns 1 through 5, we can see that the two methods agree on significance levels for eight estimated coefficients. Of those that change, thirteen estimated coefficients are deemed less significant by the randomization methods, and only five more significant.

The second experiment is the Public Goods Game in which the participants are the same as in the Trust Game. They were divided into groups, and each subject received one coin. The players secretly decide whether or not to return the coin to the administrator. If the administrator gets at least 80 percent of the coins back, then all players will receive two coins. The equilibrium of this game is that players contribute zero coins towards the public good, and no public good is provided. The counterfactual is generated by an equal probability random draw between zero and one coin to be passed to the administrator. These estimates are reported in columns 6 and 7. For the Public Goods Game, the two methods 
agree on significance levels for only one estimated coefficient and disagree for eight. Of those, randomization methods find more significant results in six cases, and less in two.

This increase in the $p$-value of an estimated coefficient as the number of draws increase is a phenomenon that may happen in the implementation of this method and merits further discussion. To explain why this can happen, let's focus on the figures reported in Table 1, which presents the expected value and standard deviation of relevant order statistics drawn from a standard normal random variable. These figures imply that as the number of draws is increased, two potentially offsetting effects occur. First, the bias (positive in absolute value) is reduced. Secondly, the standard deviation of the order statistic is reduced. The first effect will unambiguously decrease the randomized p-value, or increase the level of significance. The second effect has the potential to either increase or decrease the level of significance. Consider an estimated coefficient which is close to the 0.005 critical value. As a consequence of the theoretical dispersion of the 0.005 critical value being reduced by a greater number of draws, results formerly significant at the 0.005 level could now be no longer significant at that level, or results could become more significant. ${ }^{6}$

To evaluate the effect of more draws for the example based on Karlan (2005), we repeat Table 19 with 5,000 counterfactual draws. Results are presented in Table A.2. We find broadly similar patterns of agreement, greater, and less precision as in 400 draws. Lest these findings depend upon a single iteration, we repeat this exercise 5,000 times for the coefficient contained in the first row of Table 19, Column 7. The distributions of the order statistics for the 400- and the 5000-draw cases are shown in Figure A.8.

This application which applies the randomization-based method to Karlan (2005) is useful to illustrate that increasing the number of randomized counterfactual draws does not mechanically reduce the coefficients' $p$-values and increase the significance level of results. As a further example, in Table A.3 we repeat Karlan's Table 3 (our Table 19) for an unusual

\footnotetext{
${ }^{6}$ See Table A.1 for the descriptive statistics of the order statistics for a $t_{38}$ distribution.
} 
random number seed in which the coefficient from the first row and Column 7 is designated significant at the 1-percent level. From the distribution shown in Figure A.8, we know this to be a very unusual outcome when using 400 draws that did not once occur in repetitions using 5,000 draws. Increasing the number of counterfactual draws in practice can either increase or decrease the indicated level of significance. Regardless of the outcome, increased precision remains desirable.

\section{Conclusion}

We compare the statistical properties of critical values computed using conventional samplingbased methods with those computed by randomization-based methods. Where possible, we compute the number of counterfactual draws that are necessary to obtain critical values with roughly the same precision as those obtained using conventional methods. Using Monte Carlo methods, we compute empirical distributions of both critical $t$ values and their randomization-based equivalents. We compute type I error and statistical power under a variety of distributions and statistical models, including the ubiquitous panel difference-indifferences. Under a wide variety of variations, we find that inference based on randomized methods compares favorably with inference based on conventional OLS with clustered standard errors with as few as 200 randomized draws. The differences in performance are particularly dramatic for more complex models, such as the treatment effect in an unbalanced panel DiD with 12 clustered groups, one of which is treated.

For practitioners wishing to implement randomized inference, we find that the variance or precision of randomization-based methods is roughly comparable to that of conventional inference-based methods when $d \approx 7 n$ but not less than 200 for cases with homoskedastic data. For heteroskedastic data with $G$ cluster groups, we suggest $d \approx 7 G$ but not less than 200. Since the variance of confidence intervals obtained by randomization-based methods is inversely proportional to the number of randomized draws, $d$, greater precision can in general 
be obtained by increasing the number of draws. Our proposed number of draws should not be interpreted as the appropriate number of draws to be used by empirical researchers, but as a minimum level to achieve precision comparable to conventional statistical methods. 


\section{References}

Athey, S., And G. W. Imbens (2017): "The Econometrics of Randomized Experiments," in Handbook of Economic Field Experiments, vol. 1, pp. 73-140. Elsevier.

BARR, A. (2003): "Trust and expected trustworthiness: experimental evidence from zimbabwean villages*," The Economic Journal, 113(489), 614-630.

Cameron, A. C., J. B. Gelbach, and D. L. Miller (2008): "Bootstrap-Based Improvements for Inference with Clustered Errors," The Review of Economics and Statistics, $90(3), 414-427$.

Cameron, A. C., And D. L. Miller (2015): "A practitioner's guide to cluster-robust inference," Journal of Human Resources, 50(2), 317-372.

Carrell, S. E., M. Hoekstra, and J. E. West (2018): "The Impact of College Diversity on Behavior Toward Minorities," American Economic Journal: Economic Policy, Forthcoming.

Carrell, S. E., B. I. Sacerdote, and J. E. West (2013): "From natural variation to optimal policy? The importance of endogenous peer group formation," Econometrica, $81(3), 855-882$.

Chetty, R., A. Looney, And K. Kroft (2009): "Salience and taxation: Theory and evidence," American Economic Review, 99(4), 1145-77.

Conley, T. G., And C. R. TABer (2011): "Inference with "difference in differences" with a small number of policy changes," The Review of Economics and Statistics, 93(1), $113-125$.

Harrell, F. E., AND C. DAVIS (1982): "A new distribution-free quantile estimator," Biometrika, 69(3), 635-640. 
Karlan, D. S. (2005): "Using Experimental Economics to Measure Social Capital and Predict Financial Decisions," American Economic Review, 95(5), 1688-1699.

Kofoed, M. S., And E. MCGovney (2017): "The effect of same-gender and same-race role models on occupation choice: Evidence from randomly assigned mentors at West Point," Journal of Human Resources, pp. 0416-7838r1.

Lim, J., AND J. MEER (2017): "The impact of teacher-student gender matches: Random assignment evidence from South Korea," Journal of Human Resources, pp. 1215-7585R1.

Petzold, M. (2000): "A note on the first moment of extreme order statistics from the normal distribution," in rapport nr.: Seminar Papers, no. 2000.

Ramberg, J. S., E. J. Dudewicz, P. R. Tadikamalla, and E. F. Mykytka (1979): "A Probability Distribution and its Uses in Fitting Data," Technometrics, 21(2), 201-214.

Ruppert, D., And D. S. Matteson (2015): Statistics and Data Analysis for Financial Engineering: with $R$ examples. Springer New York, New York, NY, 2nd 2015 edn. 
Figure 1: Distributions of Estimated Parameter and 0.01 Critical Value

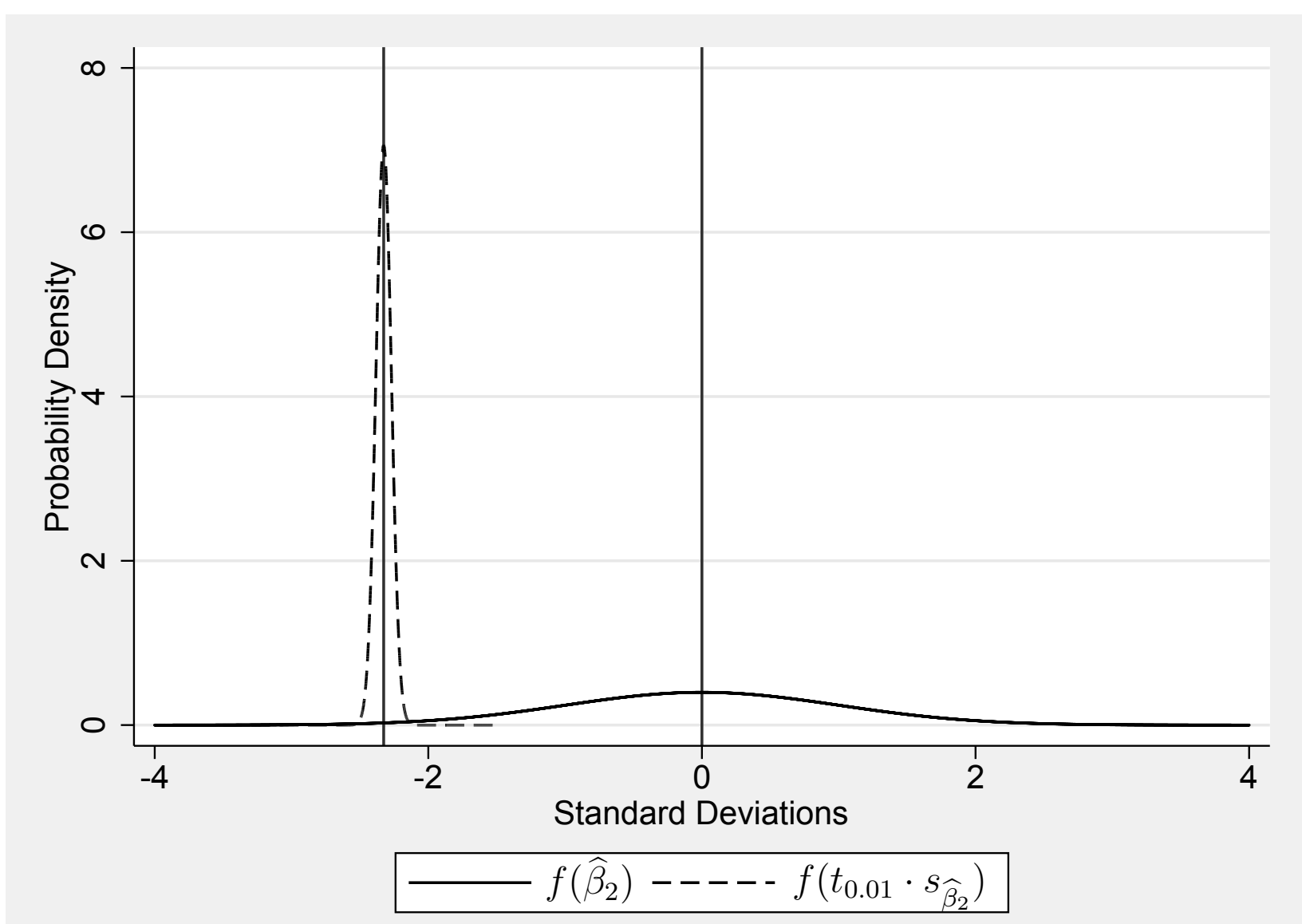

Notes: For illustrative purposes, assume $\widehat{\beta}_{2} \sim N(0,1)$ with a null hypothesis of $\beta_{2} \geq 0$, illustrated by the center vertical line. The 0.01 critical value is -2.33 illustrated by the vertical line on the left. Given the hypothesized distribution of $\widehat{\beta}_{2}$, the estimated 0.01 onesided confidence interval bound $t_{0.01, d f} \cdot s_{\widehat{\beta}_{2}}$ has a standard deviation of 0.0565 . 


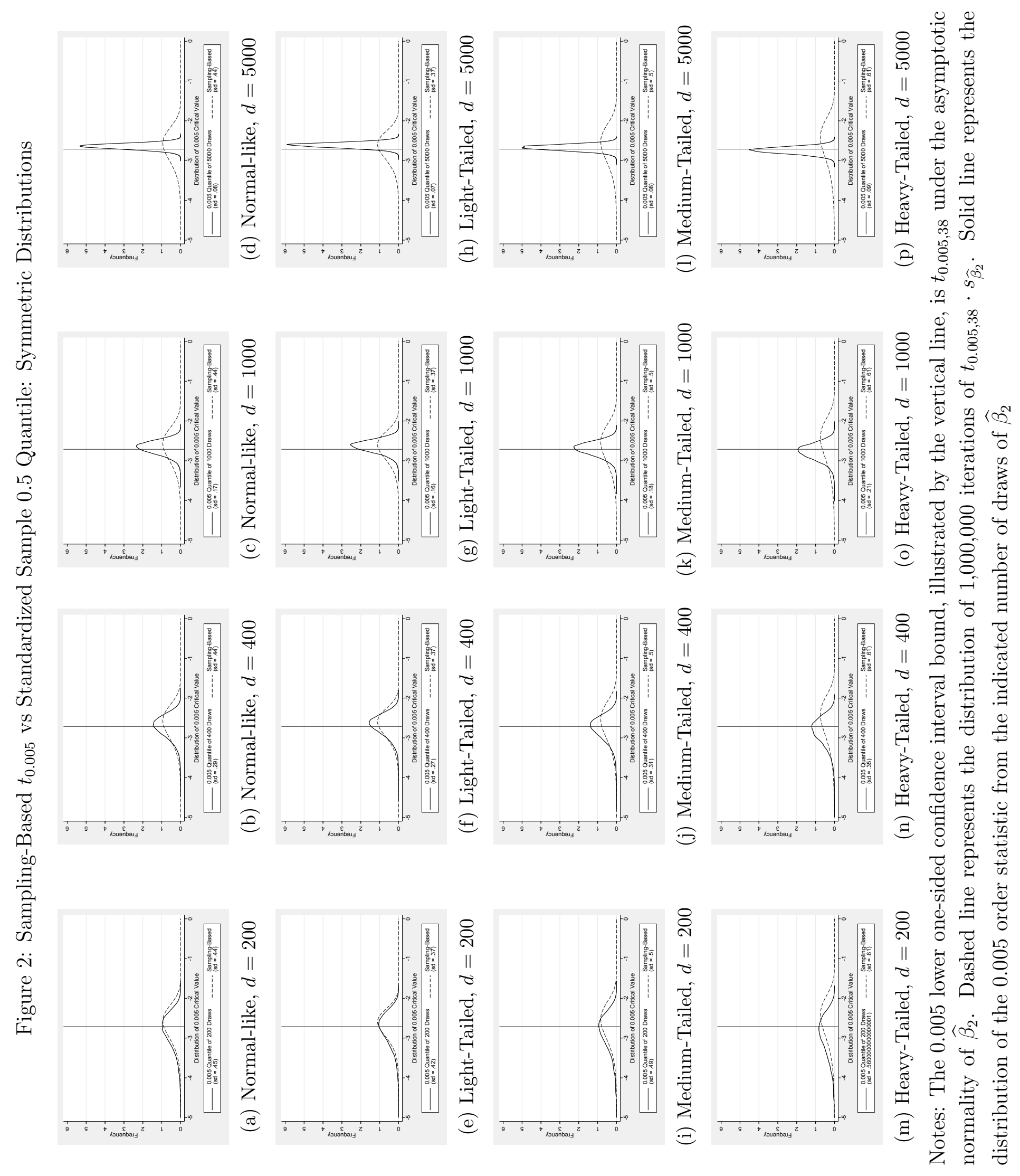




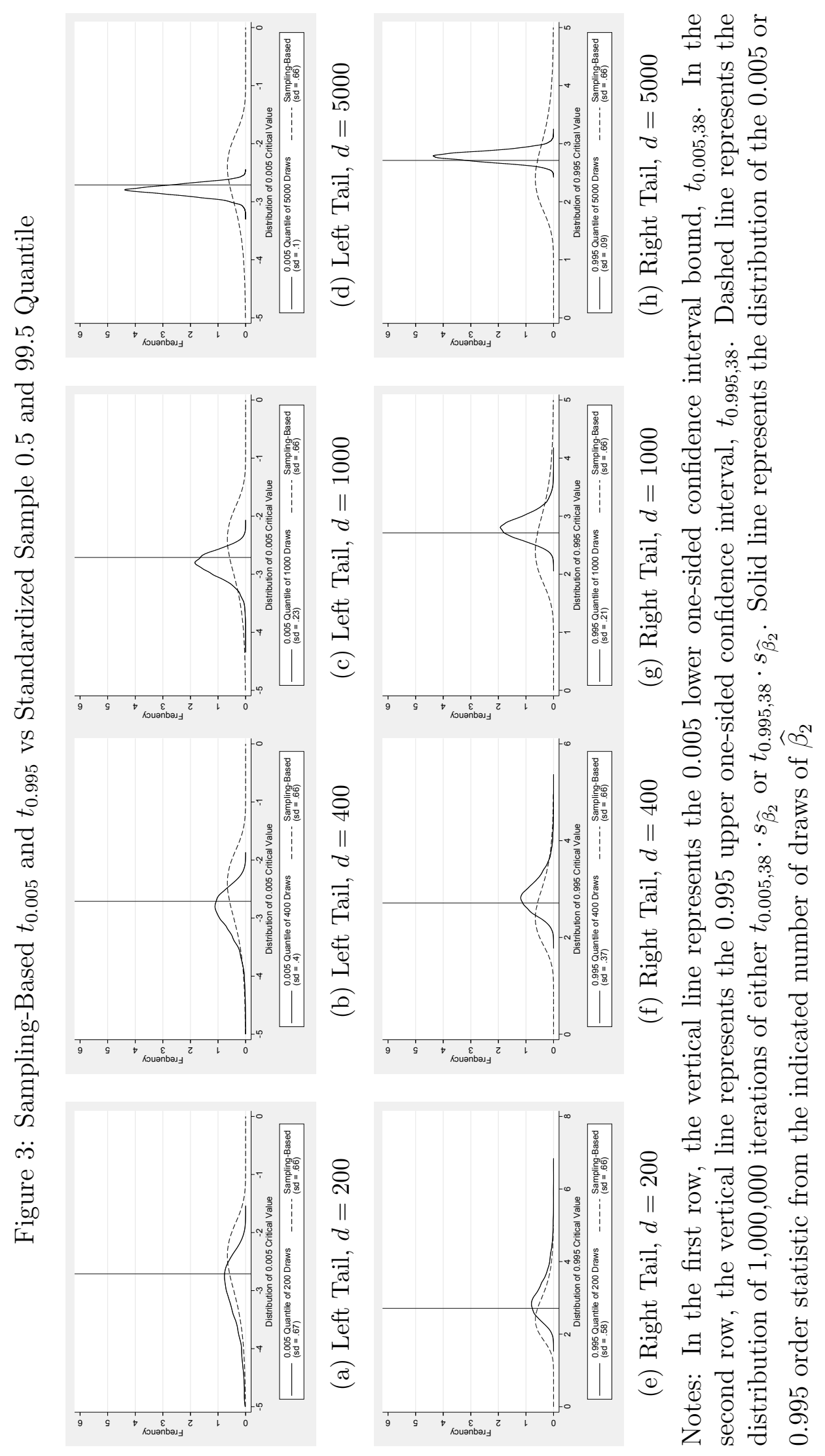


Table 1: Distribution of Standard Normal Order Statistics

\begin{tabular}{|c|c|c|c|c|c|c|}
\hline \multirow[b]{2}{*}{ Draws } & \multicolumn{2}{|c|}{$\alpha=0.005$} & \multicolumn{2}{|c|}{$\alpha=0.025$} & \multicolumn{2}{|c|}{$\alpha=0.05$} \\
\hline & $\begin{array}{l}\text { Order } \\
\text { Stat }\end{array}$ & $\begin{array}{c}\text { mean } \\
(\mathrm{sd})\end{array}$ & $\begin{array}{c}\text { Order } \\
\text { Stat }\end{array}$ & $\begin{array}{c}\text { mean } \\
(\mathrm{sd})\end{array}$ & $\begin{array}{c}\text { Order } \\
\text { Stat }\end{array}$ & $\begin{array}{c}\text { mean } \\
(\mathrm{sd})\end{array}$ \\
\hline 200 & 1 & $\begin{array}{l}-2.7460 \\
(0.4009)\end{array}$ & 5 & $\begin{array}{c}-1.9978 \\
(0.1940)\end{array}$ & 10 & $\begin{array}{r}-1.6658 \\
(0.1512)\end{array}$ \\
\hline 400 & 2 & $\begin{array}{c}-2.6576 \\
(0.2641)\end{array}$ & 10 & $\begin{array}{r}-1.9787 \\
(0.1354)\end{array}$ & 20 & $\begin{array}{r}-1.6553 \\
(0.1063)\end{array}$ \\
\hline 600 & 3 & $\begin{array}{l}-2.6295 \\
(0.2101)\end{array}$ & 15 & $\begin{array}{c}-1.9724 \\
(0.1100)\end{array}$ & 30 & $\begin{array}{r}-1.6518 \\
(0.0866)\end{array}$ \\
\hline 800 & 4 & $\begin{array}{r}-2.6157 \\
(0.1796)\end{array}$ & 20 & $\begin{array}{c}-1.9693 \\
(0.0951)\end{array}$ & 40 & $\begin{array}{r}-1.6501 \\
(0.0749)\end{array}$ \\
\hline 1,000 & 5 & $\begin{array}{l}-2.6076 \\
(0.1593)\end{array}$ & 25 & $\begin{array}{c}-1.9674 \\
(0.0849)\end{array}$ & 50 & $\begin{array}{r}-1.6490 \\
(0.0670)\end{array}$ \\
\hline 2,000 & 10 & $\begin{array}{l}-2.5915 \\
(0.1109)\end{array}$ & 50 & $\begin{array}{l}-1.9637 \\
(0.0599)\end{array}$ & 100 & $\begin{array}{r}-1.6469 \\
(0.0473)\end{array}$ \\
\hline 3,000 & 15 & $\begin{array}{l}-2.5862 \\
(0.0900)\end{array}$ & 75 & $\begin{array}{c}-1.9624 \\
(0.0489)\end{array}$ & 150 & $\begin{array}{r}-1.6462 \\
(0.0386)\end{array}$ \\
\hline 4,000 & 20 & $\begin{array}{l}-2.5836 \\
(0.0778)\end{array}$ & 100 & $\begin{array}{r}-1.9618 \\
(0.0423)\end{array}$ & 200 & $\begin{array}{r}-1.6459 \\
(0.0334)\end{array}$ \\
\hline 5,000 & 25 & $\begin{array}{c}-2.5821 \\
(0.0694)\end{array}$ & 125 & $\begin{array}{c}-1.9615 \\
(0.0378)\end{array}$ & 250 & $\begin{array}{r}-1.6457 \\
(0.0299)\end{array}$ \\
\hline 10,000 & 50 & $\begin{array}{l}-2.5789 \\
(0.0489)\end{array}$ & 250 & $\begin{array}{l}-1.9607 \\
(0.0267)\end{array}$ & 500 & $\begin{array}{r}-1.6453 \\
(0.0211)\end{array}$ \\
\hline$\Phi^{-1}(\cdot)$ & & -2.5758 & & -1.9600 & & -1.6449 \\
\hline
\end{tabular}

Notes: Expected value and standard deviation of the indicated order statistic computed using Wolfram Mathematica. The final row contains the inverse of the standard normal CDF. 
Table 2: Minimum Number of Randomized Draws to Equate Variance

\begin{tabular}{lccc}
\hline Sample & $\underline{\alpha=0.005}$ & $\frac{\alpha=0.025}{\alpha=0.05}$ & \\
Size & & & \\
$n$ & Draws & Draws & Draws \\
& $d$ & $d$ & $d$ \\
\hline & & & \\
20 & 139 & 72 & 64 \\
30 & 210 & 109 & 97 \\
40 & 282 & 146 & 130 \\
50 & 354 & 183 & 163 \\
75 & 533 & 276 & 246 \\
100 & 712 & 369 & 328 \\
250 & 1,788 & 927 & 823 \\
500 & 3,581 & 1,855 & 1,649 \\
1,000 & 7,168 & 3,713 & 3,299 \\
5,000 & 35,857 & 18,574 & 16,503 \\
10,000 & 71,720 & 37,150 & 33,008
\end{tabular}

Notes: Each cell presents the minimum number of draws to equate the variance of randomization-based quantile with the variance of the sampling-based estimated critical value at the $0.01,0.05$, and 0.10 levels of significance 


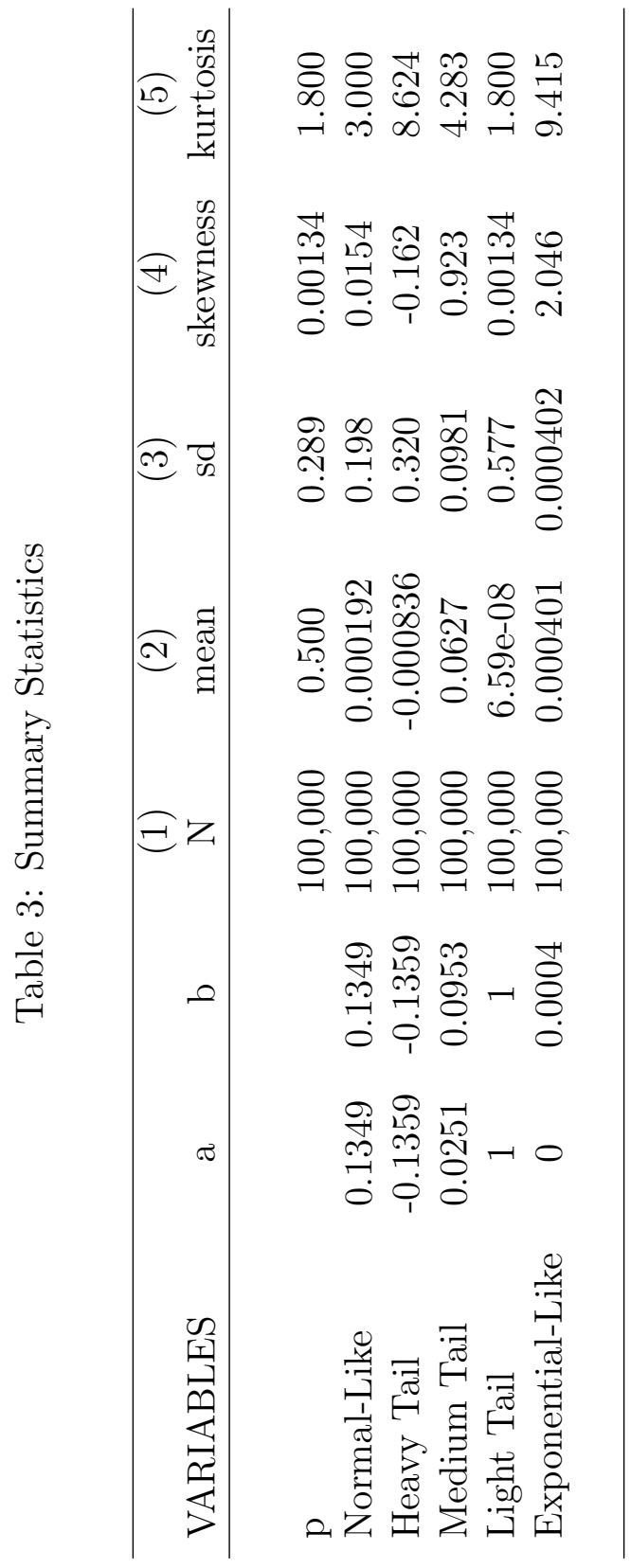


Table 4: Type I Error, Homoskedastic, Symmetric Distributions, $N=40$

\begin{tabular}{|c|c|c|c|c|c|c|c|}
\hline \multirow[b]{2}{*}{ Distribution } & \multirow[b]{2}{*}{ Draws } & (1) & $(2)$ & (3) & (4) & (5) & (6) \\
\hline & & $\begin{array}{c}t_{s} \\
(\mathrm{sd})\end{array}$ & $\begin{array}{c}t_{r} \\
(\mathrm{sd})\end{array}$ & $\begin{array}{c}t_{s} \\
(\mathrm{sd})\end{array}$ & $\begin{array}{c}t_{r} \\
(\mathrm{sd})\end{array}$ & $\begin{array}{c}t_{s} \\
(\mathrm{sd})\end{array}$ & $\begin{array}{c}t_{r} \\
(\mathrm{sd})\end{array}$ \\
\hline \multicolumn{2}{|c|}{ Panel A: Left Tail } & \multicolumn{2}{|c|}{$t_{38,0.05}=-1.686$} & \multicolumn{2}{|c|}{$t_{38,0.025}=-2.0244$} & \multicolumn{2}{|c|}{$t_{38,0.005}=-2.7116$} \\
\hline \multirow[t]{9}{*}{ Normal-Like } & \multirow[t]{2}{*}{200} & -1.6589 & -1.6625 & -1.9919 & -2.0129 & -2.6681 & -2.8383 \\
\hline & & $(0.2725)$ & $(0.1562)$ & $(0.3272)$ & $(0.2083)$ & $(0.4383)$ & $(0.4587)$ \\
\hline & \multirow[t]{2}{*}{400} & & -1.6508 & & -1.9905 & & -2.7313 \\
\hline & & & $(0.1095)$ & & $(0.1451)$ & & $(0.2963)$ \\
\hline & \multirow[t]{2}{*}{1000} & & -1.6441 & & -1.9776 & & -2.6736 \\
\hline & & & $(0.069)$ & & $(0.0907)$ & & $(0.177)$ \\
\hline & \multirow[t]{3}{*}{5,000} & & -1.64 & & -1.9702 & & -2.6444 \\
\hline & & & $(0.0308)$ & & $(0.0402)$ & & $(0.0776)$ \\
\hline & & {$[0.0517]$} & {$[0.05]$} & {$[0.026]$} & {$[0.025]$} & {$[0.0053]$} & {$[0.005]$} \\
\hline \multirow[t]{9}{*}{ Light-Tailed } & \multirow[t]{2}{*}{200} & -1.6663 & -1.6644 & -2.0008 & -2.0039 & -2.68 & -2.7919 \\
\hline & & $(0.2319)$ & $(0.1536)$ & $(0.2784)$ & $(0.2001)$ & $(0.373)$ & $(0.4298)$ \\
\hline & \multirow[t]{2}{*}{400} & & -1.6533 & & -1.9833 & & -2.6953 \\
\hline & & & $(0.1083)$ & & $(0.139)$ & & $(0.2806)$ \\
\hline & \multirow[t]{2}{*}{1000} & & -1.6468 & & -1.9716 & & -2.641 \\
\hline & & & $(0.0681)$ & & $(0.0872)$ & & $(0.1673)$ \\
\hline & \multirow[t]{3}{*}{5,000} & & -1.643 & & -1.9653 & & -2.6138 \\
\hline & & & $(0.0303)$ & & $(0.0393)$ & & $(0.0724)$ \\
\hline & & {$[0.0521]$} & {$[0.05]$} & {$[0.0263]$} & {$[0.025]$} & {$[0.0053]$} & {$[0.005]$} \\
\hline \multirow[t]{9}{*}{ Medium-Tailed } & \multirow[t]{2}{*}{200} & -1.6543 & -1.661 & -1.9863 & -2.0191 & -2.6606 & -2.8896 \\
\hline & & $(0.3088)$ & $(0.16)$ & $(0.3708)$ & $(0.213)$ & $(0.4966)$ & $(0.4982)$ \\
\hline & \multirow[t]{2}{*}{400} & & -1.649 & & -1.9967 & & -2.7715 \\
\hline & & & $(0.1125)$ & & $(0.1476)$ & & $(0.3171)$ \\
\hline & \multirow[t]{2}{*}{1000} & & -1.6415 & & -1.9835 & & -2.7079 \\
\hline & & & $(0.0705)$ & & $(0.0919)$ & & $(0.1866)$ \\
\hline & \multirow[t]{3}{*}{5,000} & & -1.6374 & & -1.9767 & & -2.6757 \\
\hline & & & $(0.0311)$ & & $(0.0406)$ & & $(0.0799)$ \\
\hline & & {$[0.0508]$} & {$[0.05]$} & {$[0.0256]$} & {$[0.025]$} & {$[0.0052]$} & {$[0.005]$} \\
\hline \multirow[t]{9}{*}{ Heavy-Tailed } & \multirow[t]{2}{*}{200} & -1.6348 & -1.6562 & -1.9629 & -2.0282 & -2.6293 & -2.9827 \\
\hline & & $(0.3804)$ & $(0.1646)$ & $(0.4568)$ & $(0.2235)$ & $(0.6118)$ & $(0.5655)$ \\
\hline & \multirow[t]{2}{*}{400} & & -1.6432 & & -2.0039 & & -2.8523 \\
\hline & & & $(0.1159)$ & & $(0.1549)$ & & $(0.3595)$ \\
\hline & \multirow[t]{2}{*}{1000} & & -1.6353 & & -1.99 & & -2.7796 \\
\hline & & & $(0.0728)$ & & $(0.0965)$ & & $(0.2135)$ \\
\hline & \multirow[t]{3}{*}{5,000} & & -1.6313 & & -1.9831 & & -2.745 \\
\hline & & & $(0.0324)$ & & $(0.0427)$ & & $(0.0923)$ \\
\hline & & {$[0.0496]$} & {$[0.05]$} & {$[0.0249]$} & {$[0.025]$} & {$[0.005]$} & {$[0.005]$} \\
\hline
\end{tabular}

Notes: $t_{s}$ represents the mean of 1,000,000 replications. With $d$ randomized draws, $t_{r}$ represents the $d \alpha$ order statistic of standardized coefficient estimates. Square brackets report Type I Error. 
Table 5: Type I Error, Homoskedastic, Exponential-Like (Asymmetric) Distribution, $N=40$

\begin{tabular}{|c|c|c|c|c|c|c|}
\hline & (1) & $(2)$ & (3) & (4) & $(5)$ & (6) \\
\hline Draws & $t_{s}$ & $t_{r}$ & $t_{s}$ & $t_{r}$ & $t_{s}$ & $t_{r}$ \\
\hline Panel A: Left Tail & \multicolumn{2}{|c|}{$t_{38,0.05}=-1.686$} & \multicolumn{2}{|c|}{$t_{38,0.025}=-2.0244$} & \multicolumn{2}{|c|}{$t_{38,0.005}=-2.7116$} \\
\hline \multirow[t]{2}{*}{200} & -1.6326 & -1.6534 & -1.9604 & -2.0419 & -2.6258 & -3.0987 \\
\hline & $(0.41)$ & $(0.1704)$ & $(0.4924)$ & $(0.2366)$ & $(0.6595)$ & $(0.676)$ \\
\hline \multirow[t]{2}{*}{400} & & -1.6398 & & -2.0166 & & -2.9307 \\
\hline & & $(0.1196)$ & & $(0.1643)$ & & $(0.409)$ \\
\hline \multirow[t]{2}{*}{1000} & & -1.6314 & & -2.0012 & & -2.8442 \\
\hline & & $(0.0753)$ & & $(0.1027)$ & & $(0.2364)$ \\
\hline \multirow[t]{3}{*}{5,000} & & -1.6268 & & -1.9928 & & -2.8002 \\
\hline & & $(0.0331)$ & & $(0.0462)$ & & $(0.1003)$ \\
\hline & {$[0.0501]$} & {$[0.05]$} & {$[0.025]$} & {$[0.025]$} & {$[0.005]$} & {$[0.005]$} \\
\hline Panel B: Right Tail & \multicolumn{2}{|c|}{$t_{38,0.950}=1.686$} & \multicolumn{2}{|c|}{$t_{38,0.975}=2.0244$} & \multicolumn{2}{|c|}{$t_{38,0.995}=2.7116$} \\
\hline \multirow[t]{2}{*}{200} & 1.6326 & 1.6317 & 1.9604 & 2.0417 & 2.6258 & 3.0401 \\
\hline & $(0.41)$ & $(0.0783)$ & $(0.4924)$ & $(0.2156)$ & $(0.6595)$ & $(0.5838)$ \\
\hline \multirow[t]{2}{*}{400} & & 1.6317 & & 2.0173 & & 2.9005 \\
\hline & & $(0.0602)$ & & $(0.1485)$ & & $(0.3697)$ \\
\hline \multirow[t]{2}{*}{1000} & & 1.6319 & & 2.0025 & & 2.8205 \\
\hline & & $(0.0461)$ & & $(0.0927)$ & & $(0.2149)$ \\
\hline \multirow[t]{3}{*}{5,000} & & 1.6318 & & 1.9954 & & 2.7843 \\
\hline & & $(0.029)$ & & $(0.0412)$ & & $(0.0924)$ \\
\hline & {$[0.9498]$} & {$[0.950]$} & {$[0.9749]$} & {$[0.975]$} & {$[0.9949]$} & {$[0.995]$} \\
\hline
\end{tabular}

Notes: $t_{s}$ represents the mean of 1,000,000 replications. With $d$ randomized draws, $t_{r}$ represents the $d \alpha$ order statistic of standardized coefficient estimates. Square brackets report Type I Error. 
Table 6: Power Table, Homoskedastic, $N=40$

\begin{tabular}{|c|c|c|c|c|c|c|c|}
\hline \multirow[b]{3}{*}{ Distribution } & \multirow[b]{3}{*}{ Draws } & (1) & $(2)$ & $(3)$ & $(4)$ & $(5)$ & $(6)$ \\
\hline & & \multicolumn{2}{|c|}{$\alpha=0.10$} & \multicolumn{2}{|c|}{$\alpha=0.05$} & \multicolumn{2}{|c|}{$\alpha=0.01$} \\
\hline & & $\begin{array}{l}\text { sampling } \\
\text { p-value }\end{array}$ & $\begin{array}{c}\text { randomized } \\
\text { p-value }\end{array}$ & $\begin{array}{c}\text { sampling } \\
\text { p-value }\end{array}$ & $\begin{array}{l}\text { randomized } \\
\text { p-value }\end{array}$ & $\begin{array}{l}\text { sampling } \\
\text { p-value }\end{array}$ & $\begin{array}{c}\text { randomized } \\
\text { p-value }\end{array}$ \\
\hline \multirow[t]{4}{*}{ Normal-Like } & 200 & .9124 & .9214 & .8503 & .8551 & .6563 & .5893 \\
\hline & 400 & & .9237 & & .8629 & & .6295 \\
\hline & 1,000 & & .9256 & & .8668 & & .6533 \\
\hline & 5,000 & & .9256 & & .8689 & & .6679 \\
\hline \multirow[t]{4}{*}{ Light-Tailed } & 200 & .2742 & .276 & .1771 & .1758 & .0592 & .0531 \\
\hline & 400 & & .2782 & & .1784 & & .056 \\
\hline & 1,000 & & .2798 & & .1793 & & .0576 \\
\hline & 5,000 & & .2798 & & .1803 & & .0583 \\
\hline \multirow{4}{*}{ Medium-Tailed } & 200 & .9998 & 1 & .9995 & 1 & .997 & .9971 \\
\hline & 400 & & 1 & & 1 & & .999 \\
\hline & 1,000 & & 1 & & .9999 & & .9993 \\
\hline & 5,000 & & 1 & & 1 & & .9994 \\
\hline \multirow[t]{4}{*}{ Heavy-Tailed } & 200 & .6244 & .6001 & .5031 & .4443 & .2735 & .1544 \\
\hline & 400 & & .6073 & & .4553 & & .1675 \\
\hline & 1,000 & & .6108 & & .4606 & & .1772 \\
\hline & 5,000 & & .6108 & & .4625 & & .183 \\
\hline \multirow[t]{4}{*}{ Exponential-Like } & 200 & 1 & 1 & 1 & 1 & 1 & 1 \\
\hline & 400 & & 1 & & 1 & & 1 \\
\hline & 1,000 & & 1 & & 1 & & 1 \\
\hline & 5,000 & & 1 & & 1 & & 1 \\
\hline
\end{tabular}

Notes: Odd numbered columns report the proportion of $t_{s}$ computed under the alternate hypothesis where $t_{s}<t_{\alpha / 2}$ or $t_{1-\alpha / 2}>t_{s}$. Even numbered columns report the proportion of $\widehat{\beta}_{2}$ computed under the alternate hypothesis where $\widehat{\beta}_{2}<\widehat{\beta}_{2(d \alpha)}$ or $\widehat{\beta}_{2(d-d \alpha+1)}$ 


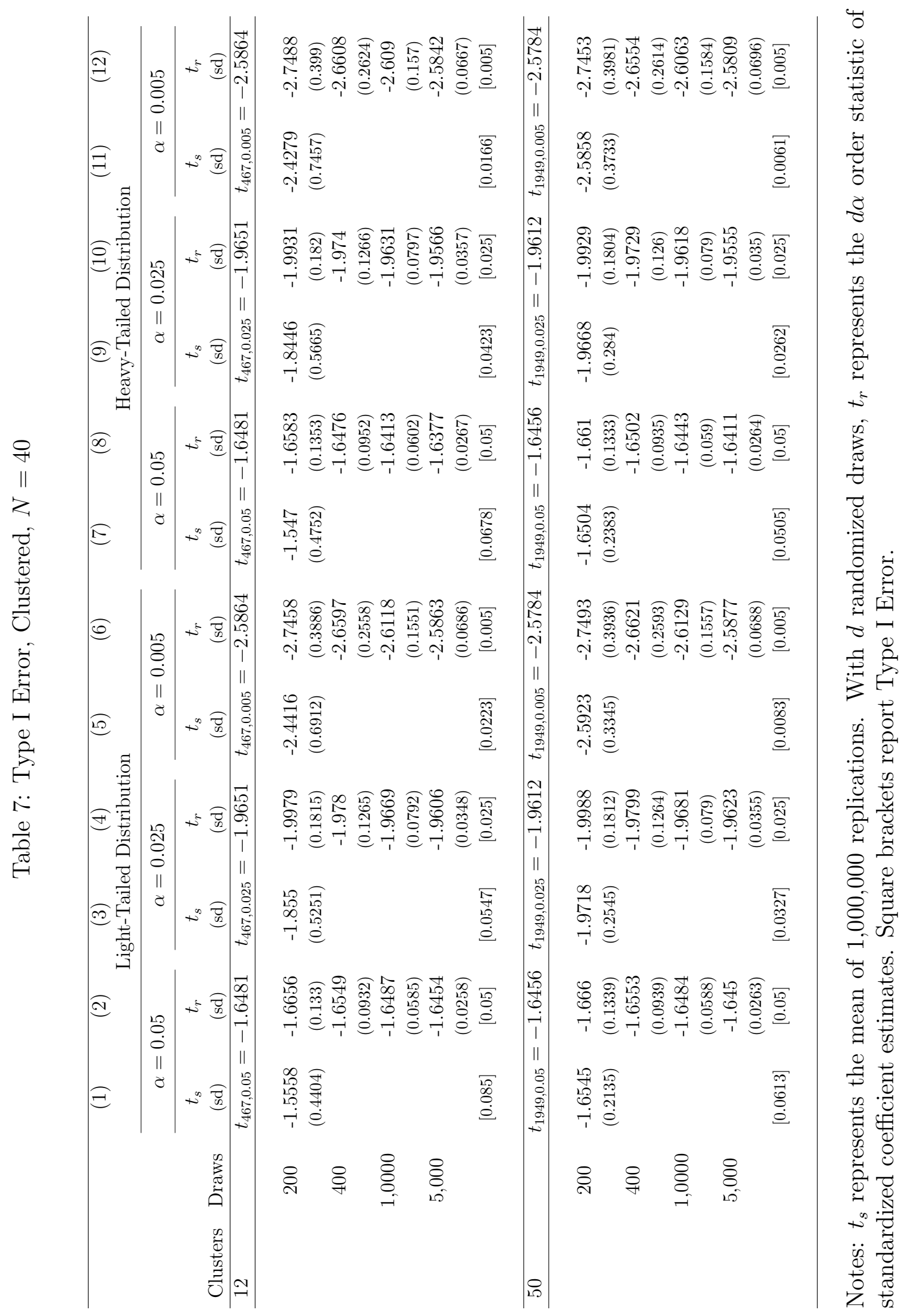


Table 8: Power Table - Clustered, $N=40$

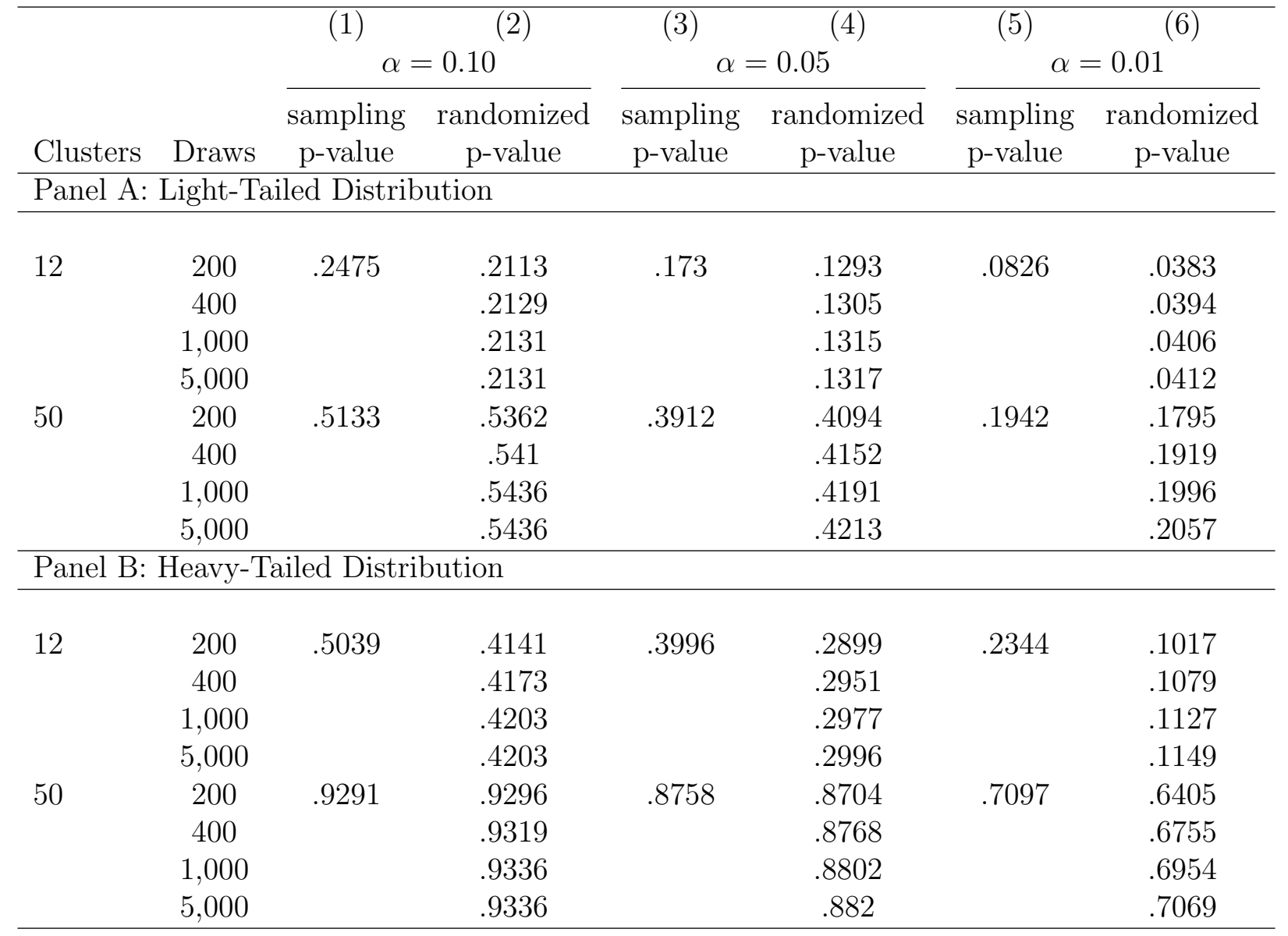

Notes: Odd numbered columns report the proportion of $t_{s}$ computed under the alternate hypothesis where $t_{s}<t_{\alpha / 2}$ or $t_{1-\alpha / 2}>t_{s}$. Even numbered columns report the proportion of $\widehat{\beta}_{2}$ computed under the alternate hypothesis where $\widehat{\beta}_{2}<\widehat{\beta}_{2(d \alpha)}$ or $\widehat{\beta}_{2(d-d \alpha+1)}$ 


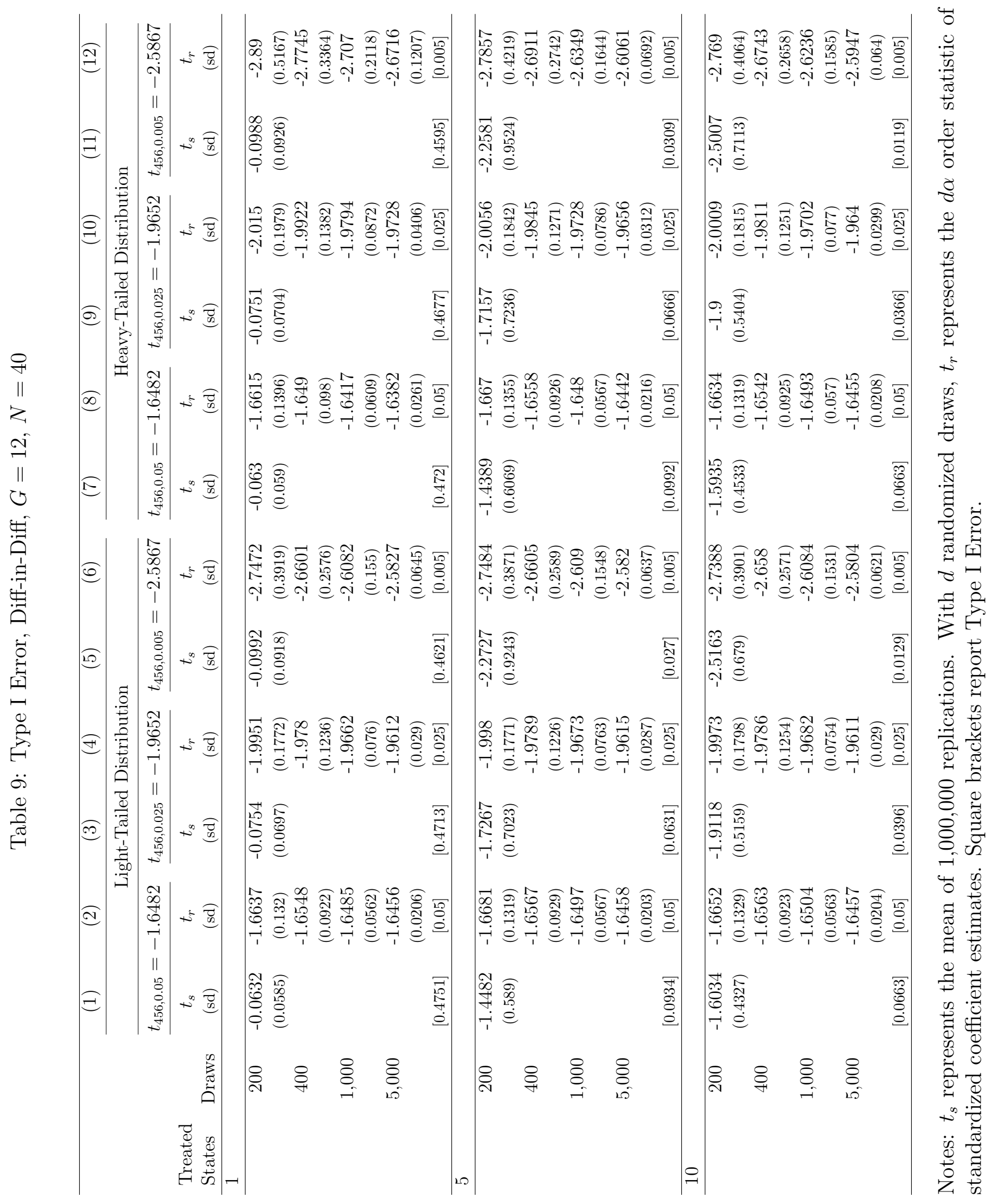


Table 10: Power Table, Diff-in-Diff, $G=12, N=40$

\begin{tabular}{|c|c|c|c|c|c|c|c|}
\hline \multirow[b]{2}{*}{$\begin{array}{l}\text { Treated } \\
\text { States }\end{array}$} & \multirow[b]{2}{*}{ Draws } & \multicolumn{2}{|c|}{$\alpha=0.10$} & \multicolumn{2}{|c|}{$\alpha=0.05$} & \multicolumn{2}{|c|}{$\alpha=0.01$} \\
\hline & & $\begin{array}{l}\text { sampling } \\
\text { p-value }\end{array}$ & $\begin{array}{l}\text { randomized } \\
\text { p-value }\end{array}$ & $\begin{array}{c}\text { sampling } \\
\text { p-value }\end{array}$ & $\begin{array}{l}\text { randomized } \\
\text { p-value }\end{array}$ & $\begin{array}{c}\text { sampling } \\
\text { p-value }\end{array}$ & $\begin{array}{l}\text { randomized } \\
\text { p-value }\end{array}$ \\
\hline \multicolumn{8}{|c|}{ Panel A: Light-Tailed Distribution } \\
\hline \multirow[t]{4}{*}{1} & 200 & .9555 & .1635 & .9472 & .0931 & .9303 & .0246 \\
\hline & 400 & & .1634 & & .0952 & & .0257 \\
\hline & 1,000 & & .1665 & & .0959 & & .0283 \\
\hline & 5,000 & & .1673 & & .0949 & & .0276 \\
\hline \multirow[t]{4}{*}{5} & 200 & .4139 & .3023 & .328 & .2013 & .2017 & .0693 \\
\hline & 400 & & .3031 & & .2069 & & .0711 \\
\hline & 1,000 & & .3035 & & .2058 & & .0755 \\
\hline & 5,000 & & .3062 & & .2058 & & .0765 \\
\hline \multirow[t]{4}{*}{10} & 200 & .5013 & .4618 & .3928 & .3395 & .2178 & .1404 \\
\hline & 400 & & .4667 & & .3439 & & .1503 \\
\hline & 1,000 & & .4699 & & .3493 & & .1543 \\
\hline & 5,000 & & .4718 & & .3508 & & .1566 \\
\hline \multicolumn{8}{|c|}{ Panel B: Heavy-Tailed Distribution } \\
\hline \multirow[t]{4}{*}{1} & 200 & .9716 & .2979 & .9655 & .1961 & .9533 & .0625 \\
\hline & 400 & & .2991 & & .1981 & & .0664 \\
\hline & 1,000 & & .302 & & .1999 & & .0684 \\
\hline & 5,000 & & .3016 & & .2003 & & .0701 \\
\hline \multirow[t]{4}{*}{5} & 200 & .6979 & .6295 & .6085 & .4937 & .445 & .2408 \\
\hline & 400 & & .6318 & & .504 & & .259 \\
\hline & 1,000 & & .6347 & & .5093 & & .2696 \\
\hline & 5,000 & & .6368 & & .5129 & & .2762 \\
\hline \multirow[t]{4}{*}{10} & 200 & .8613 & .8645 & .7863 & .7802 & .6032 & .5188 \\
\hline & 400 & & .8702 & & .7867 & & .5504 \\
\hline & 1,000 & & .8718 & & .7911 & & .5699 \\
\hline & 5,000 & & .8722 & & .7909 & & .5772 \\
\hline Observations & & $1,000,000$ & 100,000 & $1,000,000$ & 100,000 & $1,000,000$ & 100,000 \\
\hline
\end{tabular}

Notes: Odd numbered columns report the proportion of $t_{s}$ computed under the alternate hypothesis where $t_{s}<t_{\alpha / 2}$ or $t_{1-\alpha / 2}>t_{s}$. Even numbered columns report the proportion of $\widehat{\beta}_{2}$ computed under the alternate hypothesis where $\widehat{\beta}_{2}<\widehat{\beta}_{2(d \alpha)}$ or $\widehat{\beta}_{2(d-d \alpha+1)}$ 


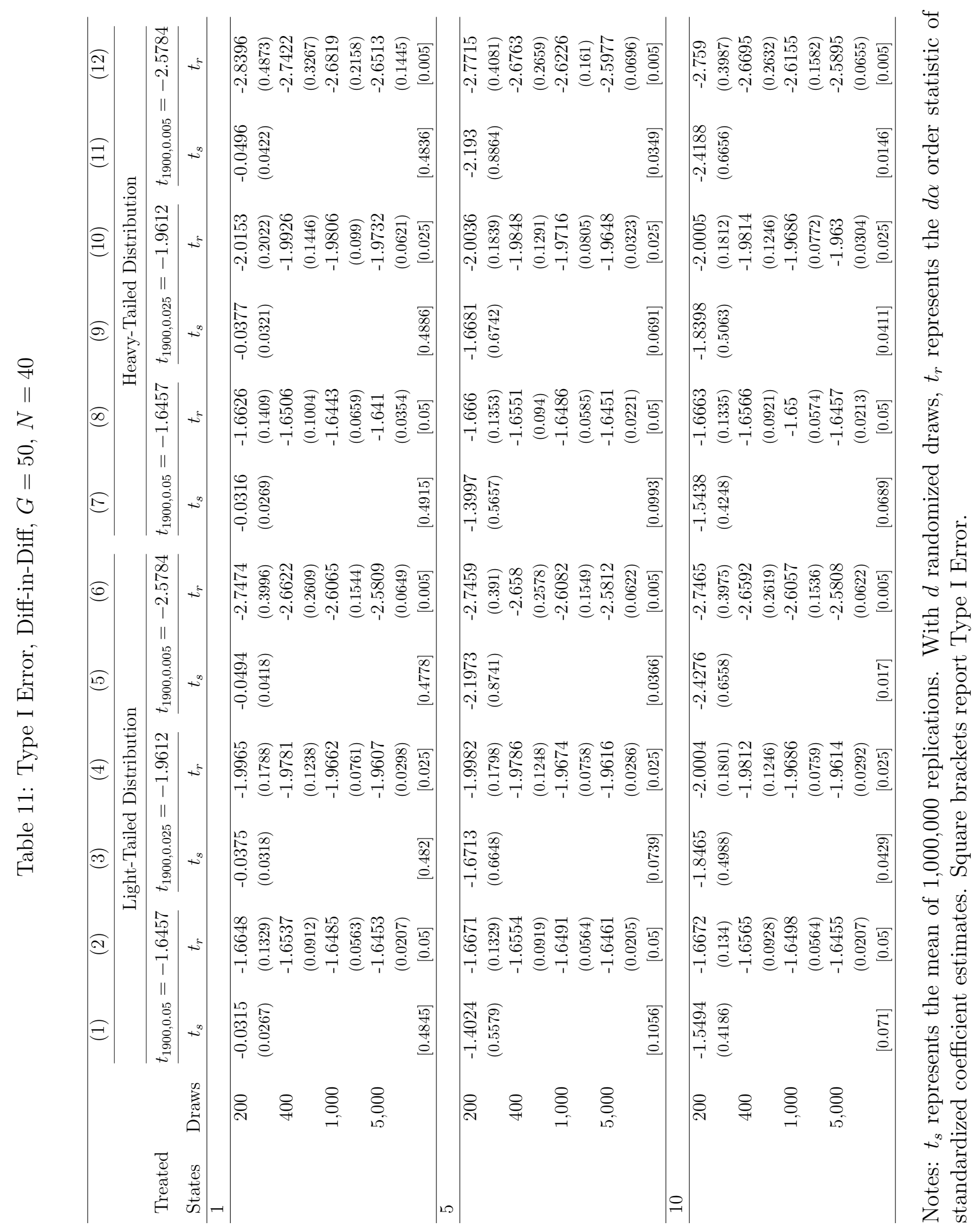


Table 12: Power Table, Diff-in-Diff, $G=50, N=40$

\begin{tabular}{|c|c|c|c|c|c|c|c|}
\hline \multirow[b]{2}{*}{$\begin{array}{l}\text { Treated } \\
\text { States }\end{array}$} & \multirow[b]{2}{*}{ Draws } & \multicolumn{2}{|c|}{$\alpha=0.10$} & \multicolumn{2}{|c|}{$\alpha=0.05$} & \multicolumn{2}{|c|}{$\alpha=0.01$} \\
\hline & & $\begin{array}{l}\text { sampling } \\
\text { p-value }\end{array}$ & $\begin{array}{l}\text { randomized } \\
\text { p-value }\end{array}$ & $\begin{array}{c}\text { sampling } \\
\text { p-value }\end{array}$ & $\begin{array}{l}\text { randomized } \\
\text { p-value }\end{array}$ & $\begin{array}{l}\text { sampling } \\
\text { p-value }\end{array}$ & $\begin{array}{l}\text { randomized } \\
\text { p-value }\end{array}$ \\
\hline \multicolumn{8}{|c|}{ Panel A: Light-Tailed Distribution } \\
\hline \multirow[t]{4}{*}{1} & 200 & .9775 & .1454 & .9729 & .0792 & .9651 & .0191 \\
\hline & 400 & & .1498 & & .0821 & & .0199 \\
\hline & 1,000 & & .1509 & & .084 & & .021 \\
\hline & 5,000 & & .1496 & & .086 & & .0214 \\
\hline \multirow[t]{4}{*}{5} & 200 & .4027 & .2904 & .3179 & .1962 & .1964 & .0649 \\
\hline & 400 & & .2935 & & .1959 & & .0703 \\
\hline & 1,000 & & .2954 & & .1972 & & .0732 \\
\hline & 5,000 & & .2974 & & .2004 & & .0731 \\
\hline \multirow[t]{4}{*}{10} & 200 & .4843 & .4468 & .3795 & .3262 & .2186 & .1251 \\
\hline & 400 & & .4533 & & .3274 & & .139 \\
\hline & 1,000 & & .4578 & & .3323 & & .1447 \\
\hline & 5,000 & & .4612 & & .3335 & & .1463 \\
\hline \multicolumn{8}{|c|}{ Panel B: Heavy-Tailed Distribution } \\
\hline \multirow[t]{4}{*}{1} & 200 & .9846 & .2589 & .9824 & .1651 & .9772 & .0516 \\
\hline & 400 & & .2609 & & .1691 & & .0527 \\
\hline & 1,000 & & .2612 & & .1702 & & .0557 \\
\hline & 5,000 & & .2621 & & .172 & & .058 \\
\hline \multirow[t]{4}{*}{5} & 200 & .6835 & .6164 & .5981 & .4881 & .438 & .2374 \\
\hline & 400 & & .6195 & & .4949 & & .2559 \\
\hline & 1,000 & & .6209 & & .4988 & & .2669 \\
\hline & 5,000 & & .623 & & .4999 & & .2715 \\
\hline \multirow[t]{4}{*}{10} & 200 & .8529 & .86 & .7784 & .7731 & .602 & .5071 \\
\hline & 400 & & .862 & & .7804 & & .5397 \\
\hline & 1,000 & & .8641 & & .7824 & & .5583 \\
\hline & 5,000 & & .8652 & & .7862 & & .5699 \\
\hline Observations & & $1,000,000$ & 100,000 & $1,000,000$ & 100,000 & $1,000,000$ & 100,000 \\
\hline
\end{tabular}

Notes: Odd numbered columns report the proportion of $t_{s}$ computed under the alternate hypothesis where $t_{s}<t_{\alpha / 2}$ or $t_{1-\alpha / 2}>t_{s}$. Even numbered columns report the proportion of $\widehat{\beta}_{2}$ computed under the alternate hypothesis where $\widehat{\beta}_{2}<\widehat{\beta}_{2(d \alpha)}$ or $\widehat{\beta}_{2(d-d \alpha+1)}$ 


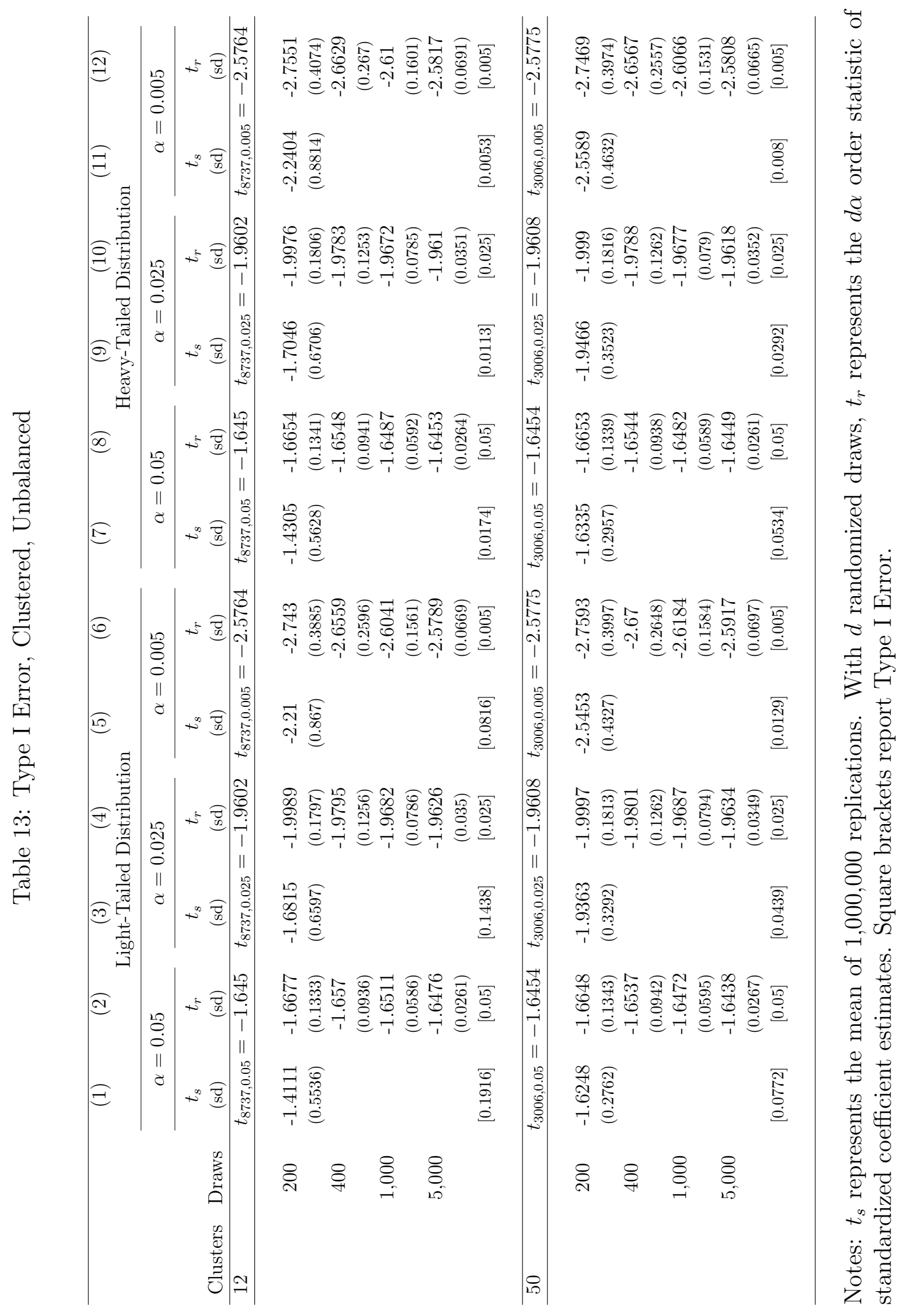


Table 14: Power Table - Clustered, Unbalanced

\begin{tabular}{|c|c|c|c|c|c|c|c|}
\hline \multirow[b]{2}{*}{ Clusters } & \multirow[b]{2}{*}{ Draws } & \multicolumn{2}{|c|}{$\alpha=0.10$} & \multicolumn{2}{|c|}{$\alpha=0.05$} & \multicolumn{2}{|c|}{$\alpha=0.01$} \\
\hline & & $\begin{array}{l}\text { sampling } \\
\text { p-value }\end{array}$ & $\begin{array}{l}\text { randomized } \\
\text { p-value }\end{array}$ & $\begin{array}{l}\text { sampling } \\
\text { p-value }\end{array}$ & $\begin{array}{l}\text { randomized } \\
\text { p-value }\end{array}$ & $\begin{array}{l}\text { sampling } \\
\text { p-value }\end{array}$ & $\begin{array}{l}\text { randomized } \\
\text { p-value }\end{array}$ \\
\hline \multicolumn{8}{|c|}{ Panel A: Light-Tailed Distribution } \\
\hline \multirow[t]{4}{*}{12} & 200 & .2314 & .1899 & .1677 & .1129 & .0902 & .0299 \\
\hline & 400 & & .1922 & & .1142 & & .0311 \\
\hline & 1,000 & & .1928 & & .115 & & .0323 \\
\hline & 5,000 & & .1928 & & 1152 & & .0333 \\
\hline \multirow[t]{4}{*}{50} & 200 & 4161 & .4557 & .3059 & .3308 & .1453 & .1345 \\
\hline & 400 & & .459 & & .3348 & & 1428 \\
\hline & 1,000 & & .462 & & .338 & & 1493 \\
\hline & 5,000 & & .462 & & .3407 & & 1521 \\
\hline \multicolumn{8}{|c|}{ Panel B: Heavy-Tailed Distribution } \\
\hline \multirow[t]{4}{*}{12} & 200 & .7458 & .3679 & .6627 & .2524 & .5023 & .0928 \\
\hline & 400 & & .3708 & & .2569 & & .0979 \\
\hline & 1,000 & & .3724 & & .2592 & & 1013 \\
\hline & 5,000 & & .3724 & & .2605 & & .1034 \\
\hline \multirow[t]{4}{*}{50} & 200 & .8684 & .8568 & .7902 & .7666 & .5886 & .496 \\
\hline & 400 & & .8608 & & .7749 & & .5299 \\
\hline & 1,000 & & .8623 & & .7794 & & .5494 \\
\hline & 5,000 & & .8623 & & .7817 & & .5606 \\
\hline
\end{tabular}

Notes: Odd numbered columns report the proportion of $t_{s}$ computed under the alternate hypothesis where $t_{s}<t_{\alpha / 2}$ or $t_{1-\alpha / 2}>t_{s}$. Even numbered columns report the proportion of $\widehat{\beta}_{2}$ computed under the alternate hypothesis where $\widehat{\beta}_{2}<\widehat{\beta}_{2(d \alpha)}$ or $\widehat{\beta}_{2(d-d \alpha+1)}$ 


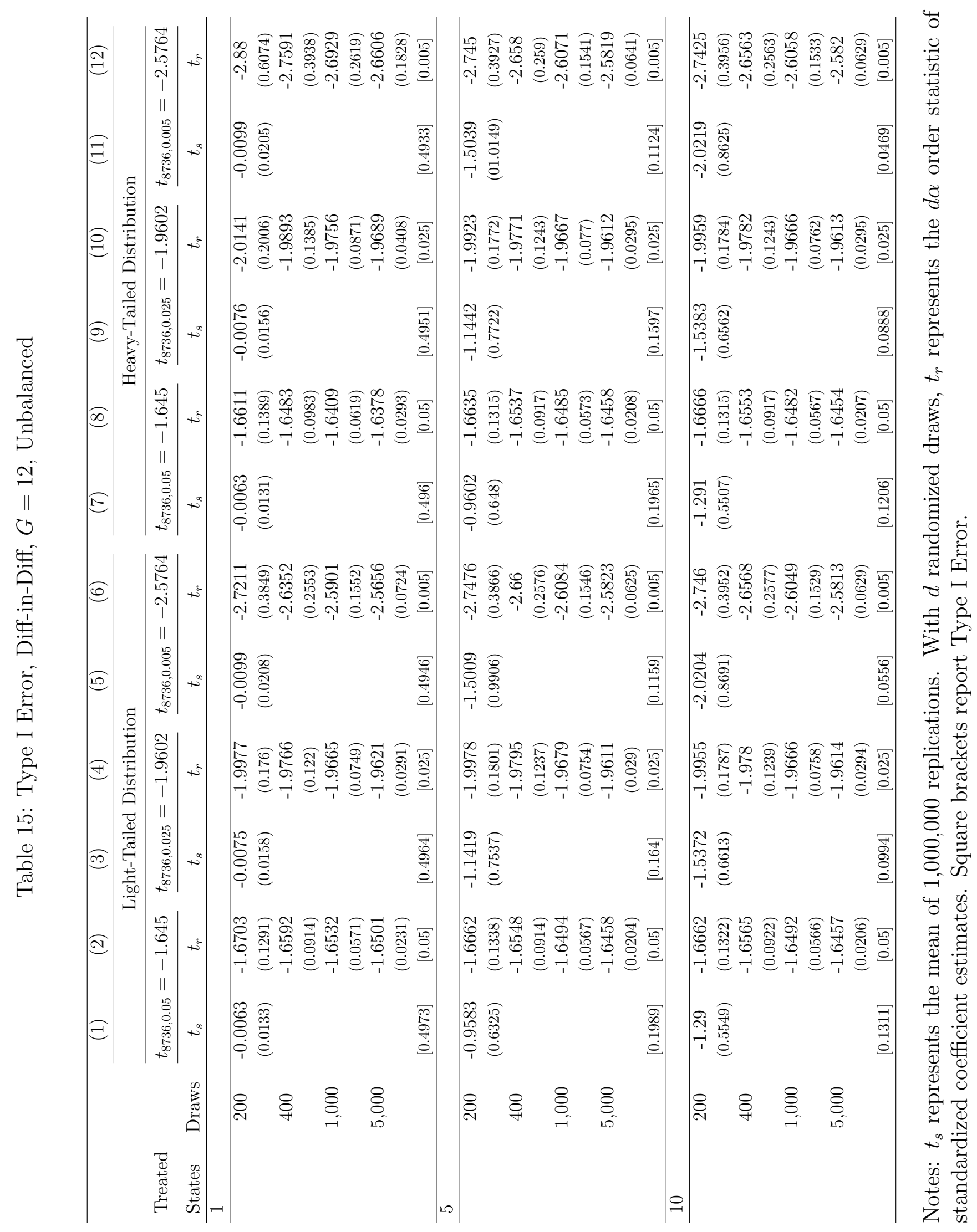


Table 16: Power Table, Diff-in-Diff, $G=12$, Unbalanced

\begin{tabular}{|c|c|c|c|c|c|c|c|}
\hline \multirow{2}{*}{$\begin{array}{l}\text { Treated } \\
\text { States }\end{array}$} & \multirow[b]{2}{*}{ Draws } & \multicolumn{2}{|c|}{$\alpha=0.10$} & \multicolumn{2}{|c|}{$\alpha=0.05$} & \multicolumn{2}{|c|}{$\alpha=0.01$} \\
\hline & & $\begin{array}{c}\text { sampling } \\
\text { p-value }\end{array}$ & $\begin{array}{c}\text { randomized } \\
\text { p-value }\end{array}$ & $\begin{array}{c}\text { sampling } \\
\text { p-value }\end{array}$ & $\begin{array}{c}\text { randomized } \\
\text { p-value }\end{array}$ & $\begin{array}{l}\text { sampling } \\
\text { p-value }\end{array}$ & $\begin{array}{c}\text { randomized } \\
\text { p-value }\end{array}$ \\
\hline \multicolumn{8}{|c|}{ Panel A: Light-Tailed Distribution } \\
\hline \multirow[t]{4}{*}{1} & 200 & .9927 & .1765 & .9918 & .1299 & .9882 & .0922 \\
\hline & 400 & & .1788 & & .1322 & & .0927 \\
\hline & 1,000 & & .1792 & & .1336 & & .0935 \\
\hline & 5,000 & & .1807 & & .1351 & & .0957 \\
\hline \multirow[t]{4}{*}{5} & 200 & .4265 & .2425 & .3599 & .1599 & .261 & .056 \\
\hline & 400 & & .2445 & & .1632 & & .0577 \\
\hline & 1,000 & & .2447 & & .164 & & .0598 \\
\hline & 5,000 & & .2468 & & .1647 & & .0612 \\
\hline \multirow[t]{4}{*}{10} & 200 & .3255 & .3039 & .2547 & .1976 & .1564 & .07 \\
\hline & 400 & & .3039 & & .2003 & & .0742 \\
\hline & 1,000 & & .3056 & & .2011 & & .0752 \\
\hline & 5,000 & & .306 & & .2031 & & .0752 \\
\hline \multicolumn{8}{|c|}{ Panel B: Heavy-Tailed Distribution } \\
\hline \multirow[t]{4}{*}{1} & 200 & .9927 & .1988 & .9913 & .1434 & .9877 & .0928 \\
\hline & 400 & & .2008 & & .1466 & & .0943 \\
\hline & 1,000 & & .2029 & & .1464 & & .0955 \\
\hline & 5,000 & & .201 & & .146 & & .0964 \\
\hline \multirow[t]{4}{*}{5} & 200 & .4978 & .4498 & .4363 & .3528 & .3328 & .1908 \\
\hline & 400 & & .4515 & & .3581 & & .2018 \\
\hline & 1,000 & & .4526 & & .3617 & & .2072 \\
\hline & 5,000 & & .4532 & & .3642 & & .2105 \\
\hline \multirow[t]{4}{*}{10} & 200 & .4719 & .6327 & .3879 & .5078 & .2655 & .2548 \\
\hline & 400 & & .6354 & & .5135 & & .2743 \\
\hline & 1,000 & & .6358 & & .5174 & & .2852 \\
\hline & 5,000 & & .638 & & .52 & & .2924 \\
\hline
\end{tabular}

Notes: Odd numbered columns report the proportion of $t_{s}$ computed under the alternate hypothesis where $t_{s}<t_{\alpha / 2}$ or $t_{1-\alpha / 2}>t_{s}$. Even numbered columns report the proportion of $\widehat{\beta}_{2}$ computed under the alternate hypothesis where $\widehat{\beta}_{2}<\widehat{\beta}_{2(d \alpha)}$ or $\widehat{\beta}_{2(d-d \alpha+1)}$ 


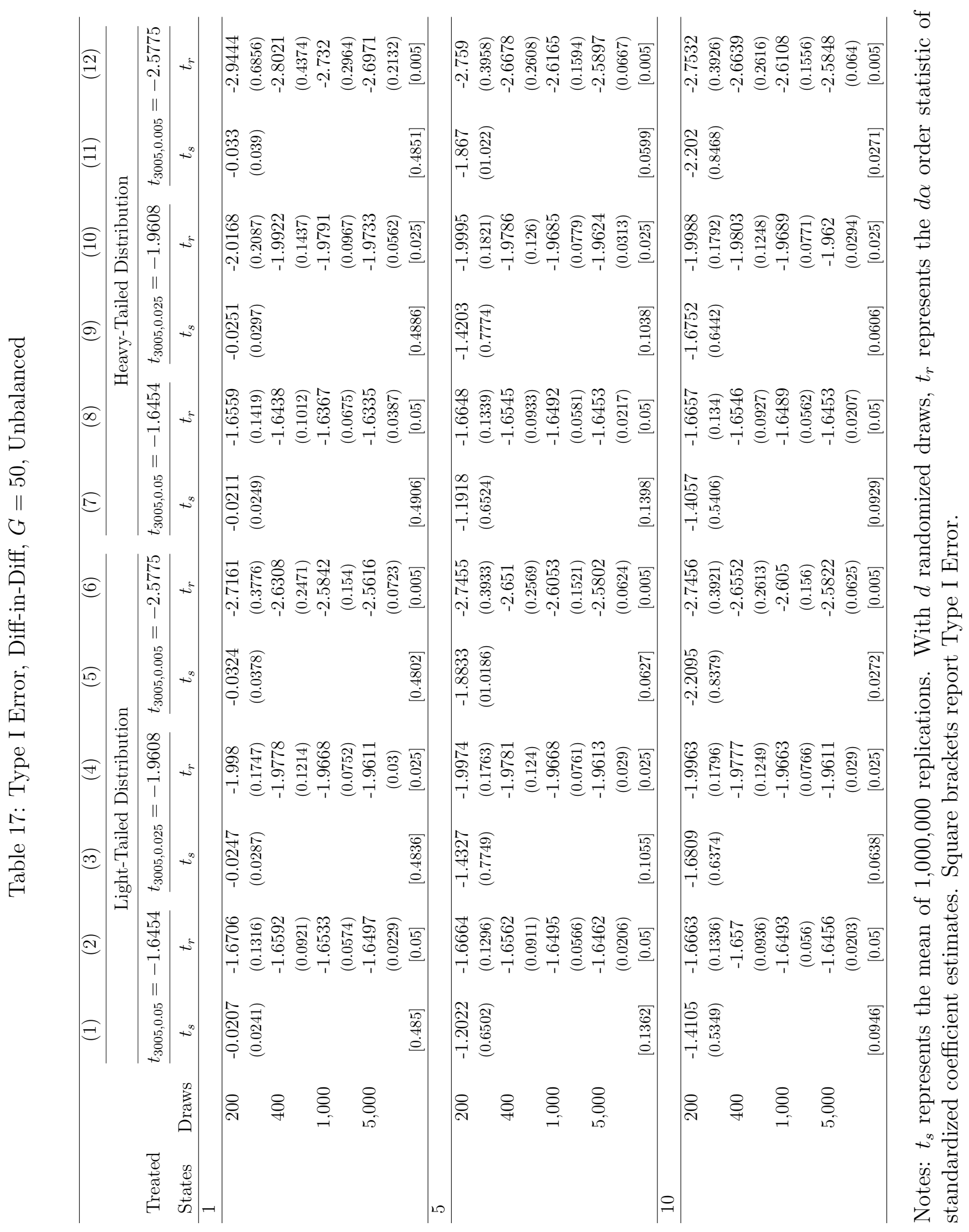


Table 18: Power Table, Diff-in-Diff, $G=50$, Unbalanced

\begin{tabular}{|c|c|c|c|c|c|c|c|}
\hline \multirow[b]{2}{*}{$\begin{array}{l}\text { Treated } \\
\text { States }\end{array}$} & \multirow[b]{2}{*}{ Draws } & \multicolumn{2}{|c|}{$\alpha=0.10$} & \multicolumn{2}{|c|}{$\alpha=0.05$} & \multicolumn{2}{|c|}{$\alpha=0.01$} \\
\hline & & $\begin{array}{c}\text { sampling } \\
\text { p-value }\end{array}$ & $\begin{array}{l}\text { randomized } \\
\text { p-value }\end{array}$ & $\begin{array}{c}\text { sampling } \\
\text { p-value }\end{array}$ & $\begin{array}{l}\text { randomized } \\
\text { p-value }\end{array}$ & $\begin{array}{l}\text { sampling } \\
\text { p-value }\end{array}$ & $\begin{array}{l}\text { randomized } \\
\text { p-value }\end{array}$ \\
\hline \multicolumn{8}{|c|}{ Panel A: Light-Tailed Distribution } \\
\hline \multirow[t]{4}{*}{1} & 200 & .9839 & .1847 & .9805 & .1167 & .9742 & .0373 \\
\hline & 400 & & .187 & & .1161 & & .0402 \\
\hline & 1,000 & & .1892 & & .1186 & & .0416 \\
\hline & 5,000 & & .1901 & & .119 & & .0408 \\
\hline \multirow[t]{4}{*}{5} & 200 & .5432 & .4132 & .4661 & .3067 & .3391 & .1345 \\
\hline & 400 & & .4159 & & .314 & & .1455 \\
\hline & 1,000 & & .4155 & & .3157 & & .1542 \\
\hline & 5,000 & & .4179 & & .3173 & & .1548 \\
\hline \multirow[t]{4}{*}{10} & 200 & .6532 & .6315 & .5626 & .5142 & .396 & .274 \\
\hline & 400 & & .636 & & .5205 & & .2922 \\
\hline & 1,000 & & .6357 & & .524 & & .3039 \\
\hline & 5,000 & & .6381 & & .525 & & .31 \\
\hline \multicolumn{8}{|c|}{ Panel B: Heavy-Tailed Distribution } \\
\hline \multirow[t]{4}{*}{1} & 200 & .9878 & .3114 & .9857 & .2205 & .9819 & .1011 \\
\hline & 400 & & .3132 & & .2242 & & .1049 \\
\hline & 1,000 & & .3129 & & .227 & & .1084 \\
\hline & 5,000 & & .3144 & & .2279 & & .1105 \\
\hline \multirow[t]{4}{*}{5} & 200 & .8093 & .7539 & .746 & .6578 & .6268 & .4289 \\
\hline & 400 & & .7566 & & .6646 & & .4511 \\
\hline & 1,000 & & .7594 & & .6661 & & .4675 \\
\hline & 5,000 & & .7596 & & .6687 & & .4759 \\
\hline \multirow[t]{4}{*}{10} & 200 & .9385 & .9449 & .901 & .9024 & .7935 & .7458 \\
\hline & 400 & & .946 & & .9069 & & .7746 \\
\hline & 1,000 & & .946 & & .9084 & & .7873 \\
\hline & 5,000 & & .9458 & & .9104 & & .7937 \\
\hline Observations & & 10,000 & 10,000 & 10,000 & 10,000 & 10,000 & 10,000 \\
\hline
\end{tabular}

Notes: Odd numbered columns report the proportion of $t_{s}$ computed under the alternate hypothesis where $t_{s}<t_{\alpha / 2}$ or $t_{1-\alpha / 2}>t_{s}$. Even numbered columns report the proportion of $\widehat{\beta}_{2}$ computed under the alternate hypothesis where $\widehat{\beta}_{2}<\widehat{\beta}_{2(d \alpha)}$ or $\widehat{\beta}_{2(d-d \alpha+1)}$ 
Table 19: Randomized vs Sampling Inference using Karlan (2005) Table 3

\begin{tabular}{|c|c|c|c|c|c|c|c|}
\hline \multirow{4}{*}{ Independent variables: } & \multicolumn{5}{|c|}{ Trust Game } & \multirow{2}{*}{\multicolumn{2}{|c|}{$\begin{array}{l}\text { Public Goods Game } \\
\text { Player characteristics }\end{array}$}} \\
\hline & \multicolumn{2}{|c|}{ Player characteristics } & \multicolumn{3}{|c|}{ Partner Characteristics } & & \\
\hline & $\begin{array}{c}\text { Proportion } \\
\text { passed } \\
\text { (Player A) }\end{array}$ & $\begin{array}{c}\text { Proportion } \\
\text { returned } \\
\text { (Player B) }\end{array}$ & $\begin{array}{l}\text { Proportion } \\
\text { passed } \\
\text { (Player A) }\end{array}$ & $\begin{array}{c}\text { Passed }>0 \\
(\text { Player A) }\end{array}$ & $\begin{array}{l}\text { Proportion } \\
\text { returned } \\
\text { (Player B) }\end{array}$ & $\begin{array}{c}\text { Binary }=1 \text { if } \\
\text { individual } \\
\text { contributed }\end{array}$ & $\begin{array}{l}\text { Proportion of } \\
\text { group that } \\
\text { contributed }\end{array}$ \\
\hline & $(1)$ & $(2)$ & $(3)$ & $(4)$ & $(5)$ & $(6)$ & $(7)$ \\
\hline \multicolumn{8}{|l|}{ Attitudinal/behavioral measures } \\
\hline Proportion passed in the Trust Game & & & & & & $\begin{array}{c}0.1159^{* *} \\
{\left[0.973^{+}\right]}\end{array}$ & $\begin{array}{l}0.1938 \\
{\left[0.983^{++}\right]}\end{array}$ \\
\hline Amount received from Player A & & $\begin{array}{c}-0.0056 \\
{[0.935]}\end{array}$ & & & & & \\
\hline Sum of 3 GSS Questions, relative to group & $\begin{array}{c}-0.0103 \\
{[0.305]}\end{array}$ & $\begin{array}{l}0.0221 \\
{[0.877]}\end{array}$ & $\begin{array}{c}-0.0052 \\
{[0.350]}\end{array}$ & $\begin{array}{c}-0.0136 \\
{[0.300]}\end{array}$ & $\begin{array}{l}0.0049 \\
{[0.532]}\end{array}$ & $\begin{array}{l}0.0183 \\
{[0.855]}\end{array}$ & \\
\hline Sum of 3 GSS Questions, relative to society & $\begin{array}{c}-0.0006 \\
{[0.532]}\end{array}$ & $\begin{array}{c}0.0383^{*} \\
{[0.922]}\end{array}$ & $\begin{array}{c}-0.0206 \\
{[0.223]}\end{array}$ & $\begin{array}{c}-0.0237 \\
{[0.223]}\end{array}$ & $\begin{array}{l}0.0009 \\
{[0.522]}\end{array}$ & $\begin{array}{c}-0.0142 \\
{[0.260]}\end{array}$ & \\
\hline Sum of 6 GSS Questions for Entire Group & & & & & & & $\begin{array}{l}0.1210^{* *} \\
{\left[1.000^{+++}\right]}\end{array}$ \\
\hline Did not maximize available debt (savings > borrowing) & $\begin{array}{c}-0.0953^{* * *} \\
{\left[0.022^{++}\right]}\end{array}$ & $\begin{array}{l}0.0184 \\
{[0.657]}\end{array}$ & $\begin{array}{l}0.0928^{*} \\
{\left[0.970^{+}\right]}\end{array}$ & $\begin{array}{l}0.0383 \\
{[0.782]}\end{array}$ & $\begin{array}{l}0.0479 \\
{[0.800]}\end{array}$ & $\begin{array}{c}-0.0765 \\
{[0.070]}\end{array}$ & $\begin{array}{c}-0.0026 \\
{[0.545]}\end{array}$ \\
\hline \multicolumn{8}{|l|}{ Connectedness to group } \\
\hline Proportion of group of similar culture & $\begin{array}{l}0.0989 \\
{[0.735]}\end{array}$ & $\begin{array}{c}-0.2120 \\
{[0.077]}\end{array}$ & $\begin{array}{l}0.2799^{*} \\
{\left[0.973^{+}\right]}\end{array}$ & $\begin{array}{l}0.4058^{*} \\
{\left[0.985^{++}\right]}\end{array}$ & $\begin{array}{l}0.1765 \\
{[0.890]}\end{array}$ & $\begin{array}{l}0.0914 \\
{[0.810]}\end{array}$ & $\begin{array}{c}0.0684 \\
{[0.610]}\end{array}$ \\
\hline Distance to others in group & $\begin{array}{l}0.1163 \\
{[0.708]}\end{array}$ & $\begin{array}{c}-0.1478^{* *} \\
{\left[0.043^{+}\right]}\end{array}$ & $\begin{array}{c}-0.0344 \\
{[0.380]}\end{array}$ & $\begin{array}{l}0.0456 \\
{[0.630]}\end{array}$ & $\begin{array}{l}0.4130^{* * *} \\
{\left[1.000^{+++}\right]}\end{array}$ & $\begin{array}{c}-0.1896^{*} \\
{\left[0.003^{+++}\right]}\end{array}$ & $\begin{array}{l}0.0783 \\
{[0.710]}\end{array}$ \\
\hline Proportion of others who live within 10-minute walk & $\begin{array}{c}-0.0881 \\
{[0.200]}\end{array}$ & $\begin{array}{l}0.0588 \\
{[0.725]}\end{array}$ & $\begin{array}{c}-0.1149 \\
{[0.170]}\end{array}$ & $\begin{array}{c}-0.0102 \\
{[0.475]}\end{array}$ & $\begin{array}{c}0.1434 \\
{[0.902]}\end{array}$ & $\begin{array}{c}-0.0613 \\
{[0.177]}\end{array}$ & \\
\hline Instances borrowing from group member in side-contract & $\begin{array}{c}-0.0412^{*} \\
{[0.080]}\end{array}$ & $\begin{array}{c}0.0170^{* *} \\
{\left[0.953^{+}\right]}\end{array}$ & $\begin{array}{l}0.003 \\
{[0.588]}\end{array}$ & $\begin{array}{c}0.0143^{*} \\
{[0.840]}\end{array}$ & $\begin{array}{c}-0.0074 \\
{[0.355]}\end{array}$ & $\begin{array}{c}0.0088^{*} \\
{[0.752]}\end{array}$ & \\
\hline Number of other members able to name form memory & $\begin{array}{l}0.0006 \\
{[0.540]}\end{array}$ & $\begin{array}{c}-0.0016 \\
{[0.343]}\end{array}$ & $\begin{array}{c}-0.0016 \\
{[0.372]}\end{array}$ & $\begin{array}{c}-0.0075 \\
{[0.058]}\end{array}$ & $\begin{array}{c}-0.0034 \\
{[0.182]}\end{array}$ & $\begin{array}{l}0.0017 \\
{[0.662]}\end{array}$ & \\
\hline \multicolumn{8}{|l|}{ Connectedness to partner } \\
\hline Partner in same lending/saving group & $\begin{array}{c}-0.0443 \\
{[0.182]}\end{array}$ & $\begin{array}{l}0.0763 \\
{[0.943]}\end{array}$ & & & & & \\
\hline Both partners indigenous & $\begin{array}{c}0.2439^{* * *} \\
{\left[0.993^{++}\right]}\end{array}$ & $\begin{array}{c}0.0406 \\
{[0.660]}\end{array}$ & & & & & \\
\hline Both players western & $\begin{array}{l}0.0522 \\
{[0.767]}\end{array}$ & $\begin{array}{c}-0.0121 \\
{[0.398]}\end{array}$ & & & & & \\
\hline Player Western; partner indigenous & $\begin{array}{l}-0.055 \\
{[0.305]}\end{array}$ & $\begin{array}{c}0.1766^{* * *} \\
{\left[0.973^{+}\right]}\end{array}$ & & & & & \\
\hline Player indigenous; partner Western & $\begin{array}{l}0.1241 \\
{[0.863]}\end{array}$ & $\begin{array}{c}-0.0200 \\
{[0.440]}\end{array}$ & & & & & \\
\hline Partner lives within 10-minute walk & $\begin{array}{c}0.0901^{* *} \\
{\left[0.960^{+}\right]}\end{array}$ & $\begin{array}{l}0.0555 \\
{[0.912]}\end{array}$ & & & & & \\
\hline Attends same small church as partner & $\begin{array}{c}0.1993^{* *} \\
{\left[0.965^{+}\right]}\end{array}$ & $\begin{array}{l}0.0450 \\
{[0.662]}\end{array}$ & & & & & \\
\hline Knew partner and her name & $\begin{array}{c}0.0444 \\
{[0.920]}\end{array}$ & $\begin{array}{c}-0.0049 \\
{[0.440]}\end{array}$ & & & & & \\
\hline Attended/Invited partner to party & $\begin{array}{l}0.0636 \\
{[0.665]}\end{array}$ & $\begin{array}{c}-0.0273 \\
{[0.425]}\end{array}$ & & & & & \\
\hline Absolute value of age difference & $\begin{array}{l}0.0009 \\
{[0.667]}\end{array}$ & $\begin{array}{l}0.0004 \\
{[0.608]}\end{array}$ & & & & & \\
\hline \multicolumn{8}{|l|}{ Demographic information } \\
\hline Completed high school & $\begin{array}{c}0.1221^{* *} \\
{\left[0.985^{++}\right]}\end{array}$ & $\begin{array}{l}0.0521 \\
{[0.875]}\end{array}$ & $\begin{array}{l}0.0408 \\
{[0.777]}\end{array}$ & $\begin{array}{l}0.0802 \\
{[0.892]}\end{array}$ & $\begin{array}{l}0.0759 \\
{\left[0.968^{+}\right]}\end{array}$ & $\begin{array}{c}-0.0339 \\
{[0.068]}\end{array}$ & \\
\hline $\ln ($ age $)$ & $\begin{array}{l}0.1055^{* *} \\
{\left[0.985^{++}\right]}\end{array}$ & $\begin{array}{l}0.0782 \\
{\left[0.963^{+}\right]}\end{array}$ & $\begin{array}{c}-0.0404 \\
{[0.200]}\end{array}$ & $\begin{array}{c}-0.0262 \\
{[0.340]}\end{array}$ & $\begin{array}{c}0.0549^{*} \\
{[0.910]}\end{array}$ & $\begin{array}{l}-0.0615 \\
{\left[0.043^{+}\right]}\end{array}$ & \\
\hline Indigenous & $\begin{array}{c}-0.0741 \\
{[0.170]}\end{array}$ & $\begin{array}{l}0.0292 \\
{[0.675]}\end{array}$ & $\begin{array}{c}0.0869^{*} \\
{[0.940]}\end{array}$ & $\begin{array}{l}0.0824 \\
{[0.887]}\end{array}$ & $\begin{array}{l}0.0912^{*} \\
{\left[0.955^{+}\right]}\end{array}$ & $\begin{array}{c}-0.0031 \\
{[0.438]}\end{array}$ & \\
\hline Western & $\begin{array}{c}-0.0017 \\
{[0.505]}\end{array}$ & $\begin{array}{l}0.0789 \\
{[0.930]}\end{array}$ & $\begin{array}{c}-0.0615 \\
{[0.113]}\end{array}$ & $\begin{array}{l}-0.0997^{*} \\
{\left[0.022^{++}\right]}\end{array}$ & $\begin{array}{c}-0.0193 \\
{[0.275]}\end{array}$ & $\begin{array}{c}-0.1204^{* * *} \\
{\left[0.000^{+++}\right]}\end{array}$ & \\
\hline Months since last attended church & $\begin{array}{c}0.0003 \\
{[0.490]}\end{array}$ & $\begin{array}{c}-0.0056 \\
{[0.367]}\end{array}$ & $\begin{array}{l}0.0134 \\
{[0.685]}\end{array}$ & $\begin{array}{l}0.0142 \\
{[0.618]}\end{array}$ & $\begin{array}{c}0.0677^{* *} \\
{[0.945]}\end{array}$ & $\begin{array}{c}-0.0454^{*} \\
{\left[0.000^{+++}\right]}\end{array}$ & \\
\hline Does not attend church & $\begin{array}{l}0.0503 \\
{[0.635]}\end{array}$ & $\begin{array}{c}-0.0504 \\
{[0.260]}\end{array}$ & $\begin{array}{l}0.2437^{* *} \\
{\left[0.995^{+++}\right]}\end{array}$ & $\begin{array}{l}0.1069 \\
{[0.840]}\end{array}$ & $\begin{array}{l}0.0271 \\
{[0.655]}\end{array}$ & $\begin{array}{c}-0.0269 \\
{[0.393]}\end{array}$ & \\
\hline Attend largest church & $\begin{array}{c}-0.0782^{*} \\
{\left[0.035^{+}\right]}\end{array}$ & $\begin{array}{c}-0.0051 \\
{[0.435]}\end{array}$ & $\begin{array}{c}-0.0781^{*} \\
{\left[0.040^{+}\right]}\end{array}$ & $\begin{array}{c}-0.0333 \\
{[0.295]}\end{array}$ & $\begin{array}{c}-0.0296 \\
{[0.163]}\end{array}$ & $\begin{array}{l}0.0555 \\
{\left[0.953^{+}\right]}\end{array}$ & \\
\hline Observations & 397 & 307 & 397 & 397 & 307 & 864 & 41 \\
\hline
\end{tabular}

Notes: Significance levels based on sampling-based inference with clustered standard errors indicated by $*, * *$, and $* * *$ for $0.10,0.05$, and 0.01 levels respectively. Randomization-based $p$-value using 400 draws appears in square brackets beneath. ${ }^{+}: p<0.05$ or $p>0.95,{ }^{++}$: $p<0.025$ or $p>0.975$, and ${ }^{+++}: p<0.005$ or $p>0.995$. 
Figure A.1: Histograms of Sample Distributions

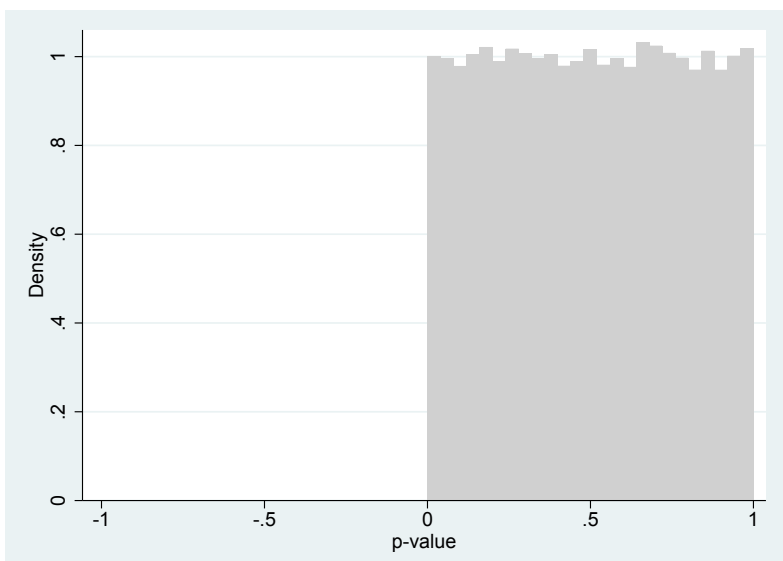

(a) p-value

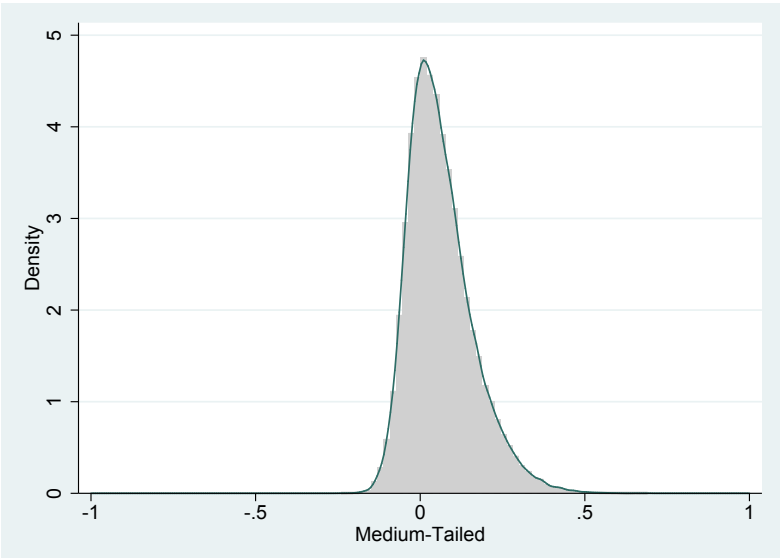

(c) Medium-Tailed

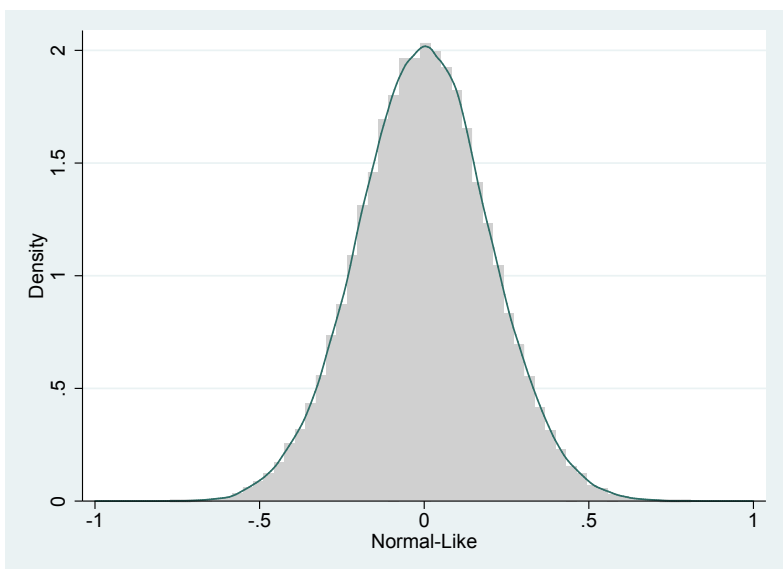

(e) Normal-Like

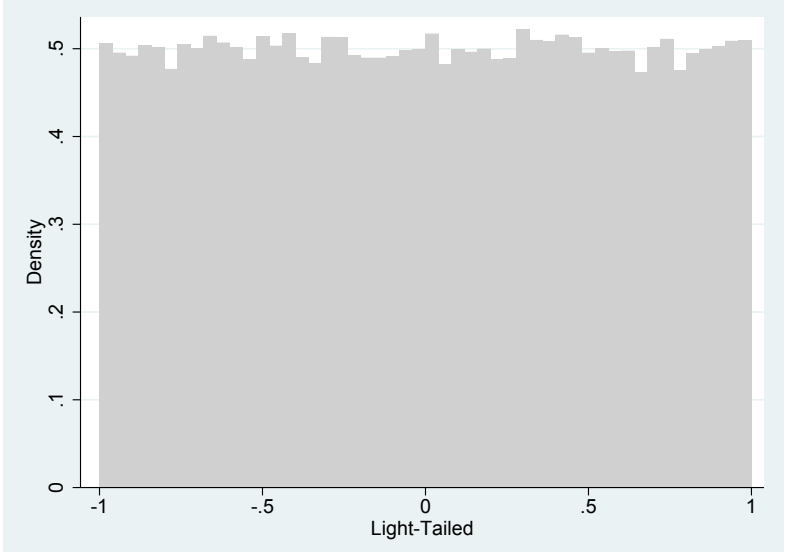

(b) Light-Tailed

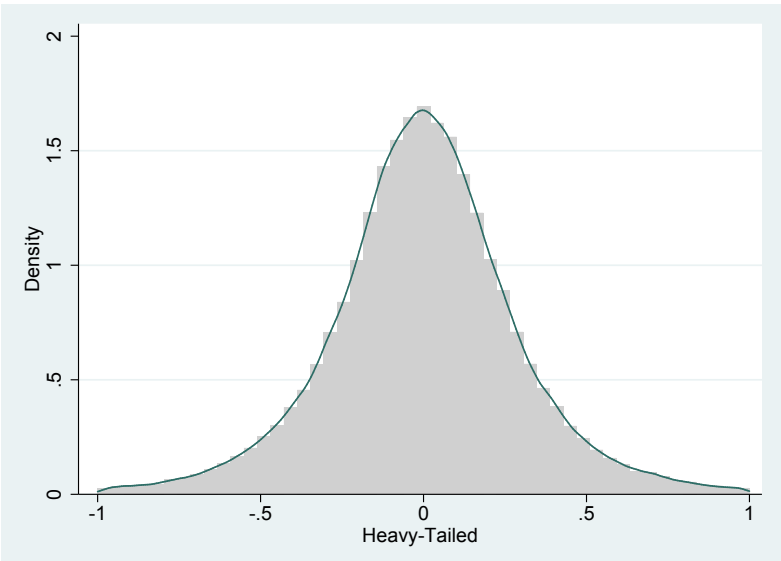

(d) Heavy-Tailed

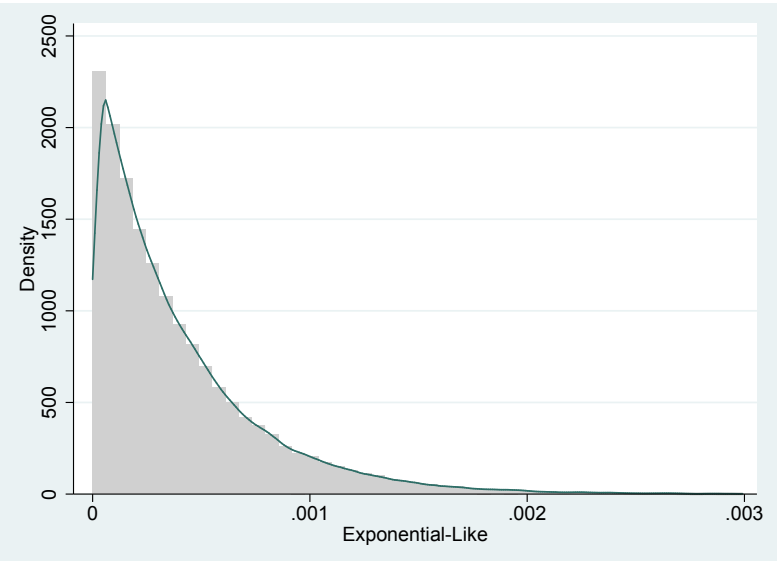

(f) Exponential

Notes: Panels (a) and (b) contain only a histogram. Panels (c) - (f) contain a kernel density estimate superimposed over the histogram. 


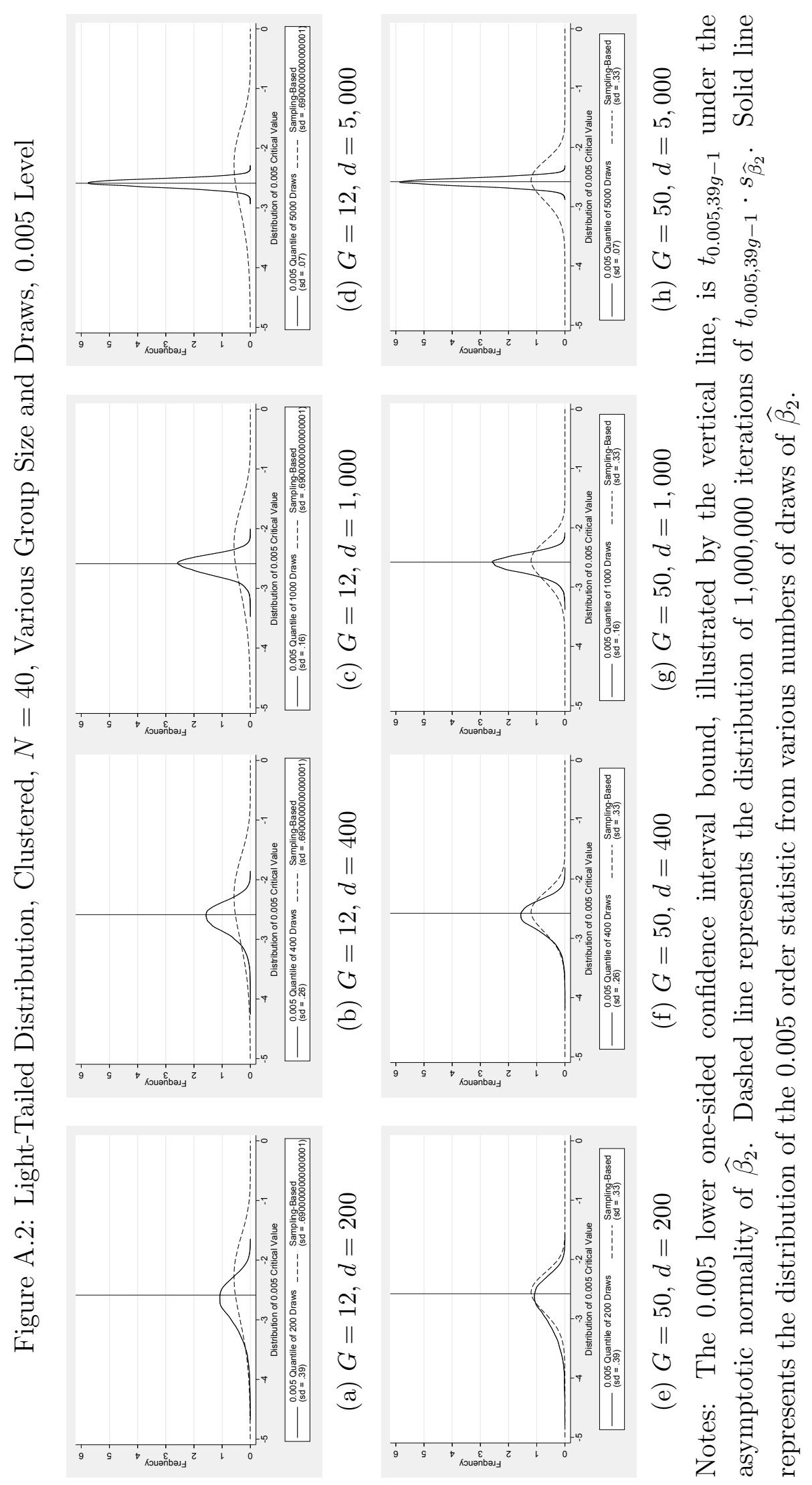




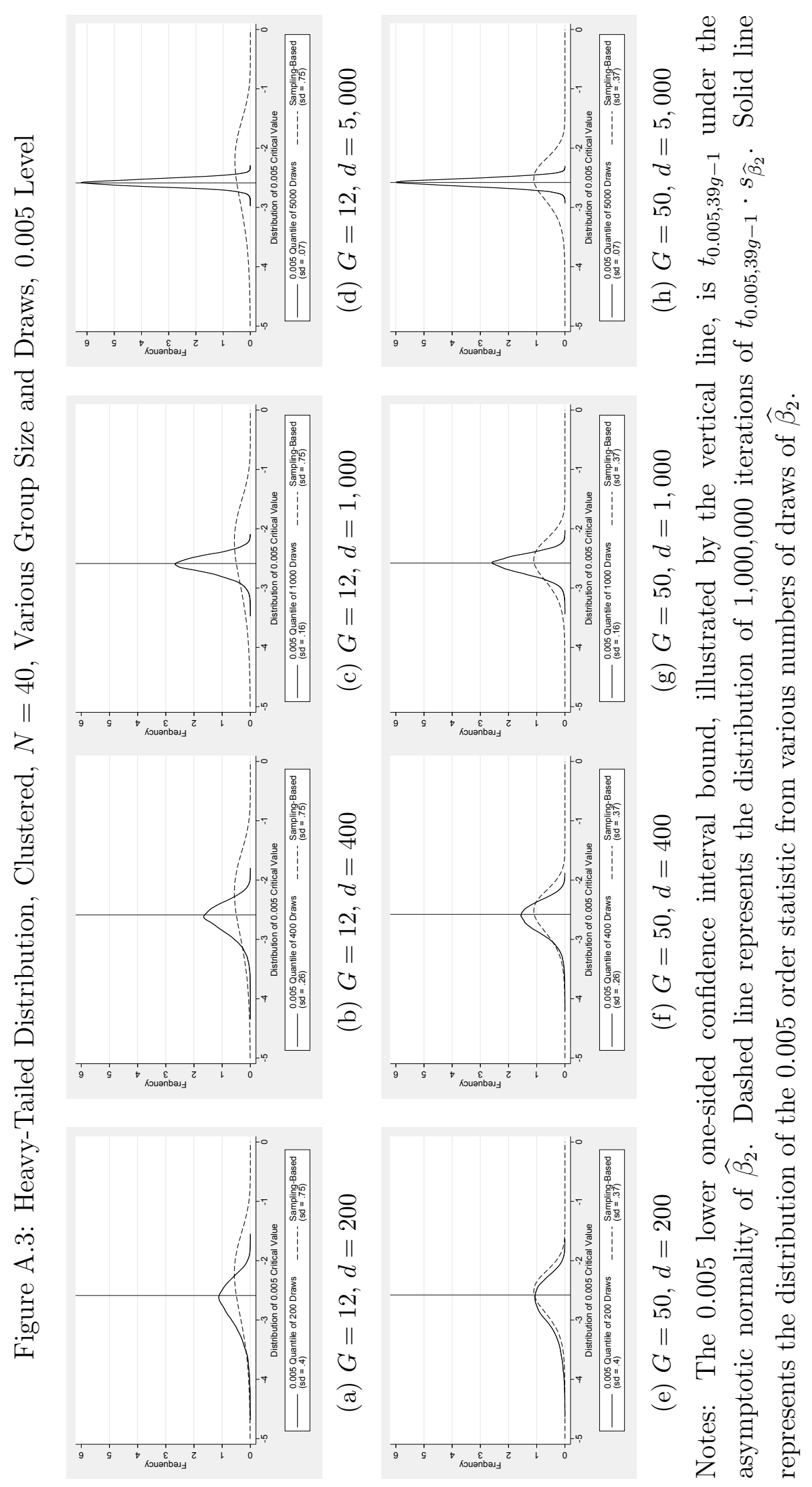




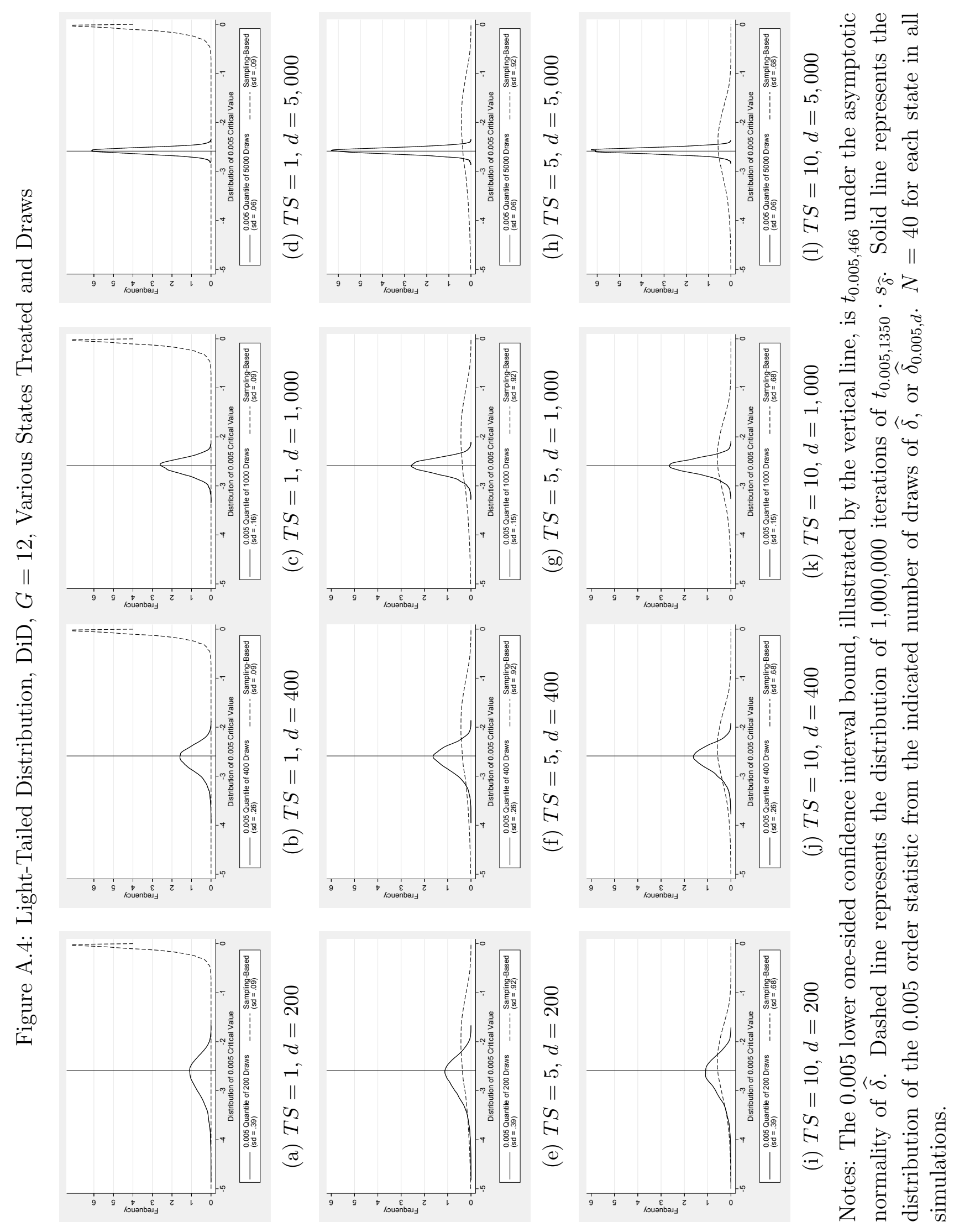




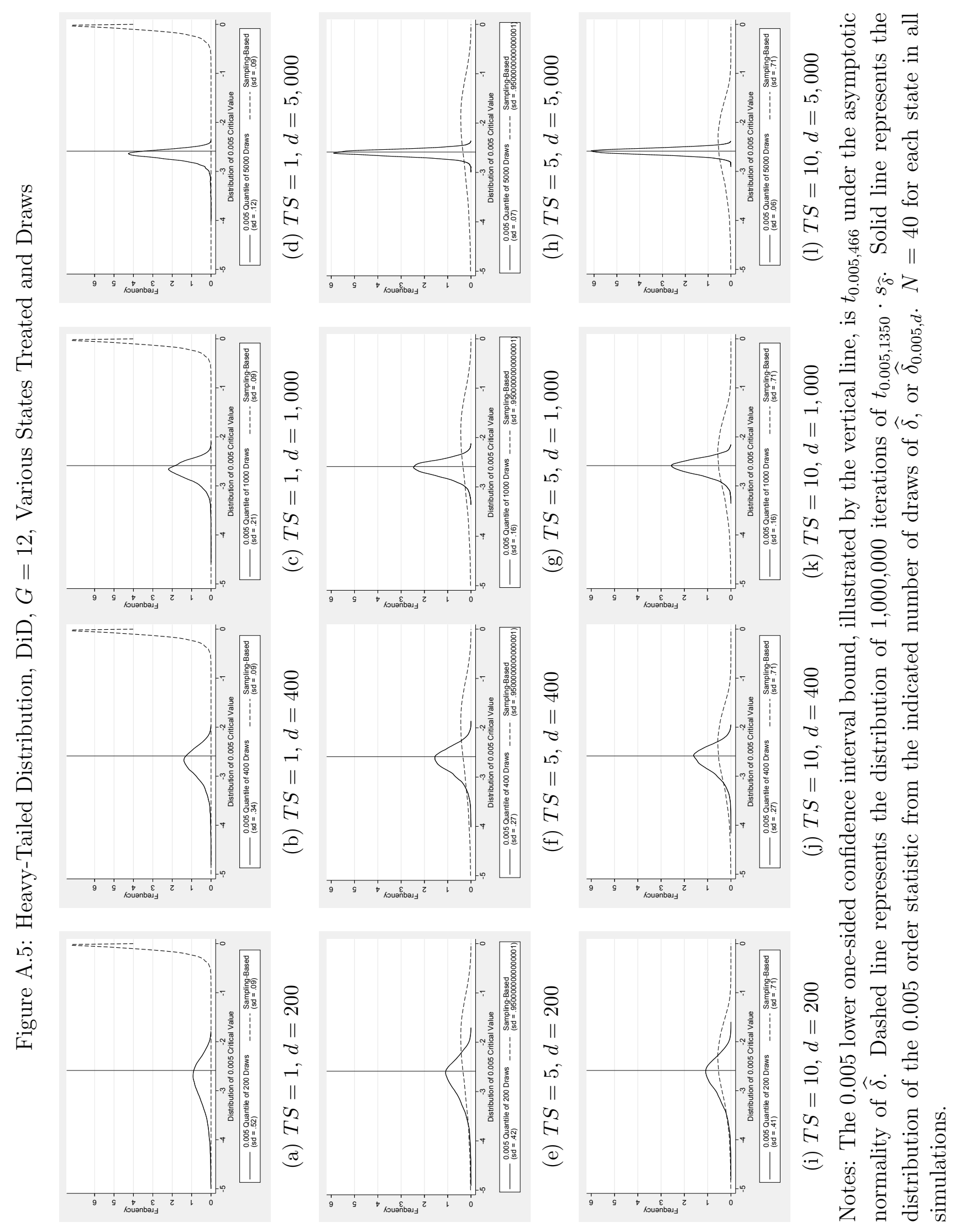




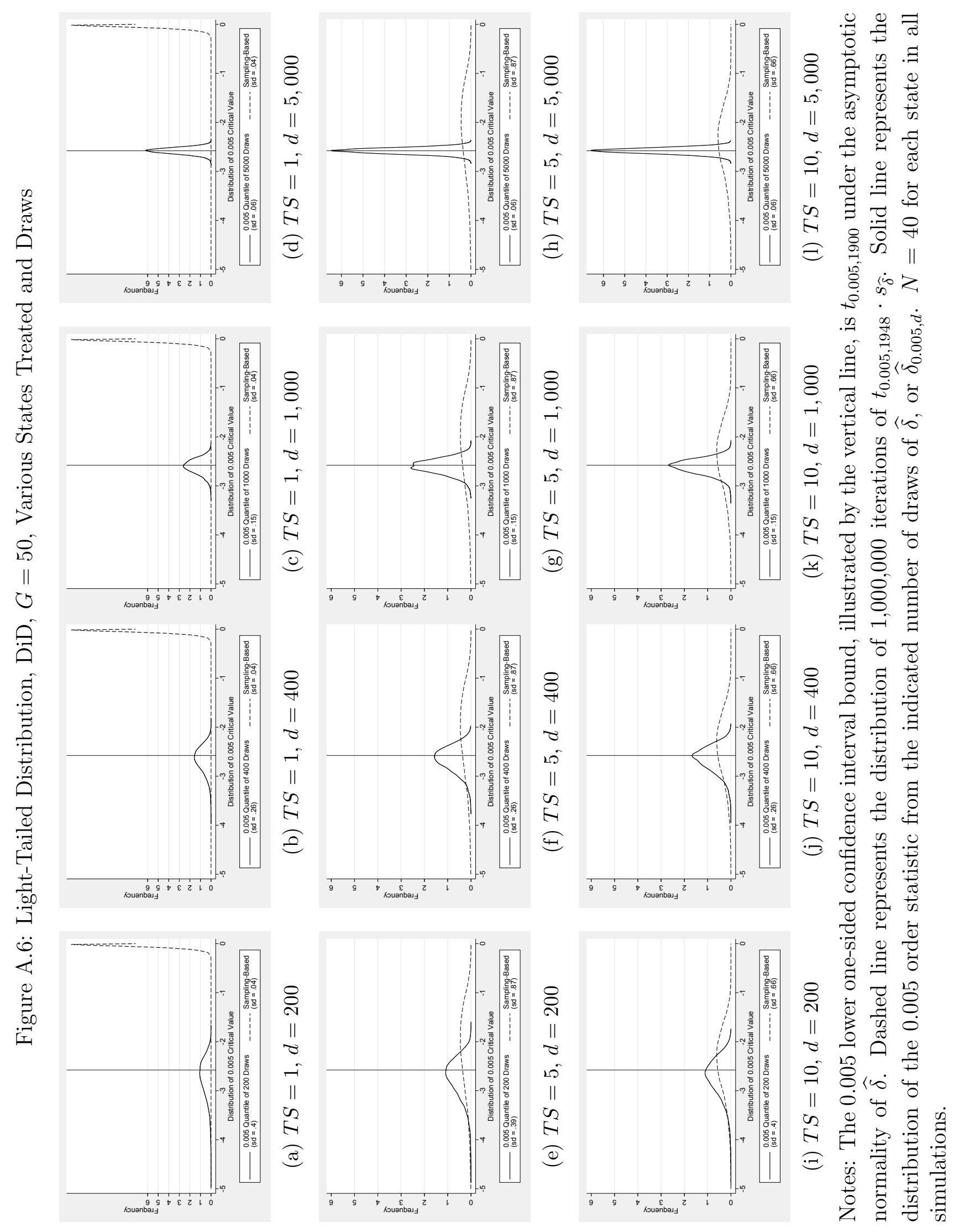




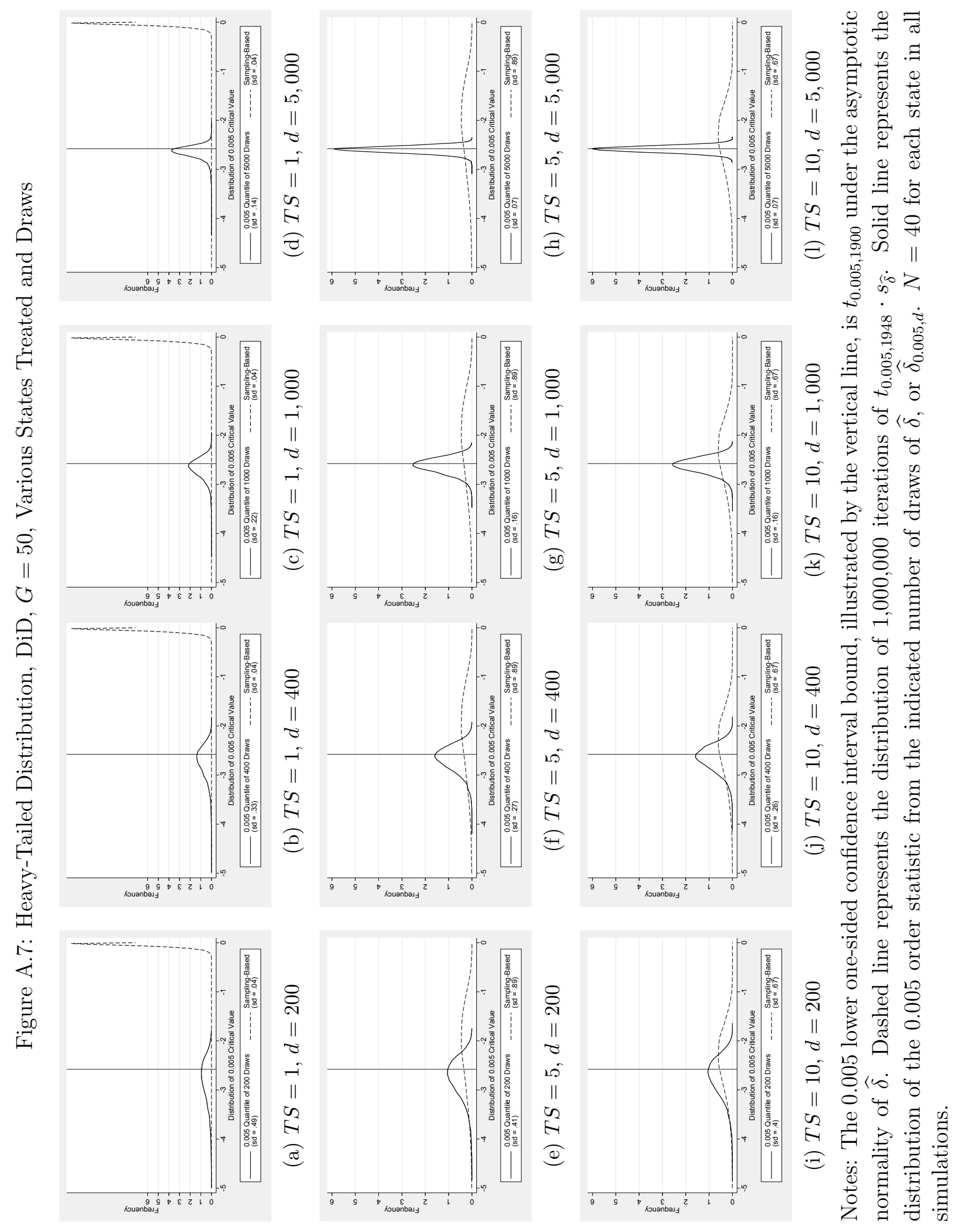


Figure A.8: Distribution of Estimates from Karlan (2005): 400 vs 5,000 Draws

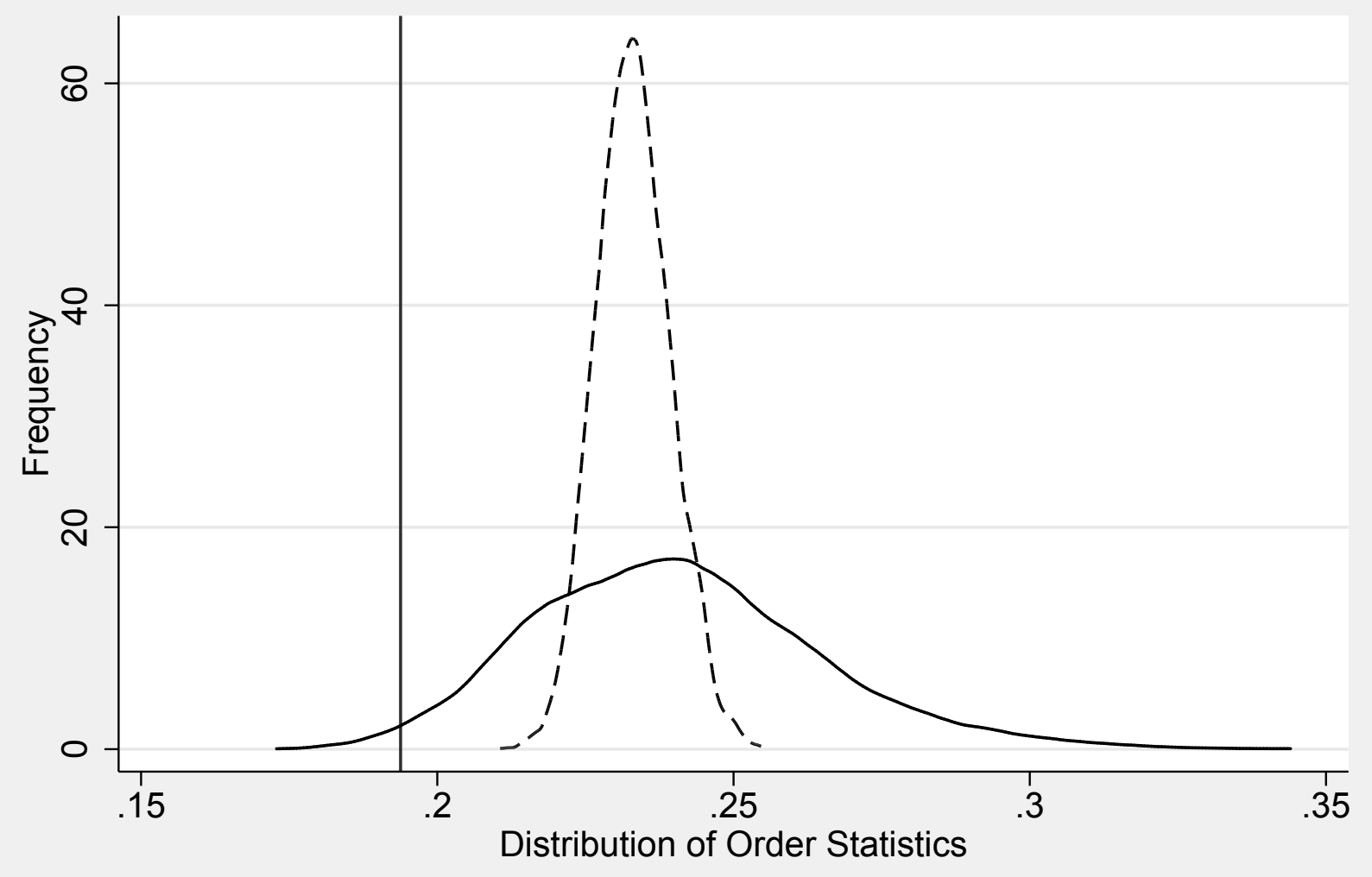

0.995 Order, 400 Draws - - - - 0.995 Order, 5,000 Draws

Notes: Distribution of estimated coefficient from line 1, column 7 using 400 and 5,000 random counterfactual draws. The vertical line represents the estimated parameter using Karlan's experimental subjects. 
Table A.1: Distribution of $t_{38}$ Order Statistics

\begin{tabular}{|c|c|c|c|c|c|c|}
\hline \multirow[b]{2}{*}{ Draws } & \multicolumn{2}{|c|}{$\alpha=0.005$} & \multicolumn{2}{|c|}{$\alpha=0.025$} & \multicolumn{2}{|c|}{$\alpha=0.05$} \\
\hline & $\begin{array}{l}\text { Order } \\
\text { Stat }\end{array}$ & $\begin{array}{c}\text { mean } \\
(\mathrm{sd})\end{array}$ & $\begin{array}{c}\text { Order } \\
\text { Stat }\end{array}$ & $\begin{array}{c}\text { mean } \\
(\mathrm{sd})\end{array}$ & $\begin{array}{l}\text { Order } \\
\text { Stat }\end{array}$ & $\begin{array}{c}\text { mean } \\
(\mathrm{sd})\end{array}$ \\
\hline 200 & 1 & $\begin{array}{c}-2.9194 \\
(0.4788)\end{array}$ & 5 & $\begin{array}{c}-2.0072 \\
(0.2120)\end{array}$ & 10 & $\begin{array}{r}-1.7091 \\
(0.1610)\end{array}$ \\
\hline 400 & 2 & $\begin{array}{l}-2.8102 \\
(0.3087)\end{array}$ & 10 & $\begin{array}{c}-2.0456 \\
(0.1475)\end{array}$ & 20 & $\begin{array}{r}-1.6975 \\
(0.1130)\end{array}$ \\
\hline 600 & 3 & $\begin{array}{r}-2.7760 \\
(0.2440)\end{array}$ & 15 & $\begin{array}{r}-2.0385 \\
(0.1198)\end{array}$ & 30 & $\begin{array}{r}-1.6936 \\
(0.0921)\end{array}$ \\
\hline 800 & 4 & $\begin{array}{c}-2.7594 \\
(0.2079)\end{array}$ & 20 & $\begin{array}{l}-2.0349 \\
(0.1034)\end{array}$ & 40 & $\begin{array}{r}-1.6907 \\
(0.0796)\end{array}$ \\
\hline 1,000 & 5 & $\begin{array}{c}-2.7496 \\
(0.1841)\end{array}$ & 25 & $\begin{array}{c}-2.0328 \\
(0.0924)\end{array}$ & 50 & $\begin{array}{r}-1.6905 \\
(0.0712)\end{array}$ \\
\hline 2,000 & 10 & $\begin{array}{r}-2.7303 \\
(0.1277)\end{array}$ & 50 & $\begin{array}{l}-2.0286 \\
(0.0651)\end{array}$ & 100 & $\begin{array}{r}-1.6882 \\
(0.0503)\end{array}$ \\
\hline 3,000 & 15 & $\begin{array}{r}-2.7240 \\
(0.1036)\end{array}$ & 75 & $\begin{array}{l}-2.0272 \\
(0.0531)\end{array}$ & 150 & $\begin{array}{r}-1.6875 \\
(0.0410)\end{array}$ \\
\hline 4,000 & 20 & $\begin{array}{c}-2.7209 \\
(0.0894)\end{array}$ & 100 & $\begin{array}{c}-2.0265 \\
(0.0460)\end{array}$ & 200 & $\begin{array}{r}-1.6871 \\
(0.0355)\end{array}$ \\
\hline 5,000 & 25 & $\begin{array}{r}-2.7190 \\
(0.0798)\end{array}$ & 125 & $\begin{array}{l}-2.0261 \\
(0.0411)\end{array}$ & 250 & $\begin{array}{r}-1.6869 \\
(0.0318)\end{array}$ \\
\hline 10,000 & 50 & $\begin{array}{c}-2.7153 \\
(0.0562)\end{array}$ & 250 & $\begin{array}{c}-2.0252 \\
(0.0290)\end{array}$ & 500 & $\begin{array}{r}-1.6864 \\
(0.0225)\end{array}$ \\
\hline$t_{38}^{-1}(\cdot)$ & & -2.7116 & & -2.0244 & & -1.6860 \\
\hline
\end{tabular}

Notes: Expected value and standard deviation of the indicated order statistic computed using Wolfram Mathematica. The final row contains the inverse of the $t_{38}$ CDF. 
Table A.2: Randomized vs Sampling Inference using Karlan (2005) Table 3

\begin{tabular}{|c|c|c|c|c|c|c|c|}
\hline \multirow{4}{*}{ Independent variables: } & \multicolumn{5}{|c|}{ Trust Game } & \multirow{2}{*}{\multicolumn{2}{|c|}{$\begin{array}{c}\text { Public Goods Game } \\
\text { Player characteristics }\end{array}$}} \\
\hline & \multicolumn{2}{|c|}{ Player characteristics } & \multicolumn{3}{|c|}{ Partner Characteristics } & & \\
\hline & $\begin{array}{c}\text { Proportion } \\
\text { passed } \\
\text { (Player A) }\end{array}$ & $\begin{array}{c}\text { Proportion } \\
\text { returned } \\
\text { (Player B) }\end{array}$ & $\begin{array}{l}\text { Proportion } \\
\text { passed } \\
\text { (Player A) }\end{array}$ & $\begin{array}{c}\text { Passed }>0 \\
(\text { Player A) }\end{array}$ & $\begin{array}{c}\text { Proportion } \\
\text { returned } \\
\text { (Player B) }\end{array}$ & $\begin{array}{c}\text { Binary }=1 \text { if } \\
\text { individual } \\
\text { contributed }\end{array}$ & $\begin{array}{l}\text { Proportion of } \\
\text { group that } \\
\text { contributed }\end{array}$ \\
\hline & $(1)$ & $(2)$ & $(3)$ & $(4)$ & $(5)$ & $(6)$ & $(7)$ \\
\hline \multicolumn{8}{|l|}{ Attitudinal/behavioral measures } \\
\hline Proportion passed in the Trust Game & & & & & & $\begin{array}{c}0.1159^{* *} \\
{\left[0.975^{++}\right]}\end{array}$ & $\begin{array}{c}0.1938 \\
{\left[0.984^{++}\right]}\end{array}$ \\
\hline Amount received from Player A & & $\begin{array}{c}-0.0056 \\
{[0.944]}\end{array}$ & & & & & \\
\hline Sum of 3 GSS Questions, relative to group & $\begin{array}{c}-0.0103 \\
{[0.321]}\end{array}$ & $\begin{array}{l}0.0221 \\
{[0.870]}\end{array}$ & $\begin{array}{c}-0.0052 \\
{[0.405]}\end{array}$ & $\begin{array}{c}-0.0136 \\
{[0.305]}\end{array}$ & $\begin{array}{l}0.0049 \\
{[0.541]}\end{array}$ & $\begin{array}{l}0.0183 \\
{[0.873]}\end{array}$ & \\
\hline Sum of 3 GSS Questions, relative to society & $\begin{array}{c}-0.0006 \\
{[0.499]}\end{array}$ & $\begin{array}{c}0.0383^{*} \\
{[0.920]}\end{array}$ & $\begin{array}{c}-0.0206 \\
{[0.244]}\end{array}$ & $\begin{array}{c}-0.0237 \\
{[0.248]}\end{array}$ & $\begin{array}{l}0.0009 \\
{[0.539]}\end{array}$ & $\begin{array}{c}-0.0142 \\
{[0.251]}\end{array}$ & \\
\hline Sum of 6 GSS Questions for Entire Group & & & & & & & $\begin{array}{l}0.1210^{* *} \\
{\left[1.000^{+++}\right]}\end{array}$ \\
\hline Did not maximize available debt (savings $>$ borrowing) & $\begin{array}{c}-0.0953^{* * *} \\
{\left[0.030^{+}\right]}\end{array}$ & $\begin{array}{l}0.0184 \\
{[0.652]}\end{array}$ & $\begin{array}{l}0.0928^{*} \\
{\left[0.962^{+}\right]}\end{array}$ & $\begin{array}{l}0.0383 \\
{[0.723]}\end{array}$ & $\begin{array}{l}0.0479 \\
{[0.825]}\end{array}$ & $\begin{array}{c}-0.0765 \\
{[0.055]}\end{array}$ & $\begin{array}{c}-0.0026 \\
{[0.501]}\end{array}$ \\
\hline \multicolumn{8}{|l|}{ Connectedness to group } \\
\hline Proportion of group of similar culture & $\begin{array}{l}0.0989 \\
{[0.715]}\end{array}$ & $\begin{array}{c}-0.2120 \\
{[0.080]}\end{array}$ & $\begin{array}{l}0.2799^{*} \\
{\left[0.958^{+}\right]}\end{array}$ & $\begin{array}{l}0.4058^{*} \\
{\left[0.984^{++}\right]}\end{array}$ & $\begin{array}{r}0.1765 \\
{[0.893]}\end{array}$ & $\begin{array}{l}0.0914 \\
{[0.836]}\end{array}$ & $\begin{array}{c}0.0684 \\
{[0.643]}\end{array}$ \\
\hline Distance to others in group & $\begin{array}{l}0.1163 \\
{[0.721]}\end{array}$ & $\begin{array}{c}-0.1478^{* *} \\
{[0.065]}\end{array}$ & $\begin{array}{c}-0.0344 \\
{[0.369]}\end{array}$ & $\begin{array}{l}0.0456 \\
{[0.612]}\end{array}$ & $\begin{array}{l}0.4130^{* * *} \\
{\left[0.997^{+++}\right]}\end{array}$ & $\begin{array}{l}-0.1896^{*} \\
{\left[0.005^{+++}\right]}\end{array}$ & $\begin{array}{l}0.0783 \\
{[0.709]}\end{array}$ \\
\hline Proportion of others who live within 10-minute walk & $\begin{array}{c}-0.0881 \\
{[0.244]}\end{array}$ & $\begin{array}{l}0.0588 \\
{[0.720]}\end{array}$ & $\begin{array}{c}-0.1149 \\
{[0.160]}\end{array}$ & $\begin{array}{c}-0.0102 \\
{[0.457]}\end{array}$ & $\begin{array}{c}0.1434 \\
{[0.895]}\end{array}$ & $\begin{array}{c}-0.0613 \\
{[0.157]}\end{array}$ & \\
\hline Instances borrowing from group member in side-contract & $\begin{array}{c}-0.0412^{*} \\
{[0.074]}\end{array}$ & $\begin{array}{c}0.0170^{* *} \\
{[0.944]}\end{array}$ & $\begin{array}{l}0.003 \\
{[0.579]}\end{array}$ & $\begin{array}{c}0.0143^{*} \\
{[0.831]}\end{array}$ & $\begin{array}{c}-0.0074 \\
{[0.349]}\end{array}$ & $\begin{array}{c}0.0088^{*} \\
{[0.757]}\end{array}$ & \\
\hline Number of other members able to name form memory & $\begin{array}{l}0.0006 \\
{[0.546]}\end{array}$ & $\begin{array}{c}-0.0016 \\
{[0.334]}\end{array}$ & $\begin{array}{c}-0.0016 \\
{[0.372]}\end{array}$ & $\begin{array}{c}-0.0075 \\
{[0.086]}\end{array}$ & $\begin{array}{c}-0.0034 \\
{[0.164]}\end{array}$ & $\begin{array}{l}0.0017 \\
{[0.660]}\end{array}$ & \\
\hline \multicolumn{8}{|l|}{ Connectedness to partner } \\
\hline Partner in same lending/saving group & $\begin{array}{c}-0.0443 \\
{[0.193]}\end{array}$ & $\begin{array}{l}0.0763 \\
{[0.945]}\end{array}$ & & & & & \\
\hline Both partners indigenous & $\begin{array}{c}0.2439^{* * *} \\
{\left[0.989^{++}\right]}\end{array}$ & $\begin{array}{c}0.0406 \\
{[0.679]}\end{array}$ & & & & & \\
\hline Both players western & $\begin{array}{l}0.0522 \\
{[0.782]}\end{array}$ & $\begin{array}{c}-0.0121 \\
{[0.425]}\end{array}$ & & & & & \\
\hline Player Western; partner indigenous & $\begin{array}{r}-0.055 \\
{[0.278]}\end{array}$ & $\begin{array}{c}0.1766^{* * *} \\
{\left[0.987^{++}\right]}\end{array}$ & & & & & \\
\hline Player indigenous; partner Western & $\begin{array}{l}0.1241 \\
{[0.875]}\end{array}$ & $\begin{array}{c}-0.0200 \\
{[0.432]}\end{array}$ & & & & & \\
\hline Partner lives within 10-minute walk & $\begin{array}{c}0.0901^{* *} \\
{\left[0.961^{+}\right]}\end{array}$ & $\begin{array}{l}0.0555 \\
{[0.899]}\end{array}$ & & & & & \\
\hline Attends same small church as partner & $\begin{array}{c}0.1993^{* *} \\
{\left[0.961^{+}\right]}\end{array}$ & $\begin{array}{l}0.0450 \\
{[0.684]}\end{array}$ & & & & & \\
\hline Knew partner and her name & $\begin{array}{c}0.0444 \\
{[0.929]}\end{array}$ & $\begin{array}{c}-0.0049 \\
{[0.448]}\end{array}$ & & & & & \\
\hline Attended/Invited partner to party & $\begin{array}{l}0.0636 \\
{[0.680]}\end{array}$ & $\begin{array}{c}-0.0273 \\
{[0.418]}\end{array}$ & & & & & \\
\hline Absolute value of age difference & $\begin{array}{l}0.0009 \\
{[0.677]}\end{array}$ & $\begin{array}{l}0.0004 \\
{[0.589]}\end{array}$ & & & & & \\
\hline $\begin{array}{l}\text { Demographic information } \\
\text { Completed high school }\end{array}$ & $\begin{array}{l}0.1221^{* *} \\
{\left[0.983^{++}\right]}\end{array}$ & $\begin{array}{l}0.0521 \\
{[0.875]}\end{array}$ & $\begin{array}{l}0.0408 \\
{[0.764]}\end{array}$ & $\begin{array}{l}0.0802 \\
{[0.898]}\end{array}$ & $\begin{array}{l}0.0759 \\
{\left[0.967^{+}\right]}\end{array}$ & $\begin{array}{c}-0.0339 \\
{[0.080]}\end{array}$ & \\
\hline $\ln ($ age $)$ & $\begin{array}{l}0.1055^{* *} \\
{\left[0.989^{++}\right]}\end{array}$ & $\begin{array}{c}0.0782 \\
{\left[0.979^{++}\right]}\end{array}$ & $\begin{array}{c}-0.0404 \\
{[0.193]}\end{array}$ & $\begin{array}{c}-0.0262 \\
{[0.326]}\end{array}$ & $\begin{array}{c}0.0549^{*} \\
{[0.917]}\end{array}$ & $\begin{array}{l}-0.0615 \\
{\left[0.040^{+}\right]}\end{array}$ & \\
\hline Indigenous & $\begin{array}{c}-0.0741 \\
{[0.180]}\end{array}$ & $\begin{array}{l}0.0292 \\
{[0.664]}\end{array}$ & $\begin{array}{c}0.0869^{*} \\
{[0.931]}\end{array}$ & $\begin{array}{l}0.0824 \\
{[0.890]}\end{array}$ & $\begin{array}{l}0.0912^{*} \\
{\left[0.964^{+}\right]}\end{array}$ & $\begin{array}{c}-0.0031 \\
{[0.465]}\end{array}$ & \\
\hline Western & $\begin{array}{c}-0.0017 \\
{[0.491]}\end{array}$ & $\begin{array}{l}0.0789 \\
{[0.913]}\end{array}$ & $\begin{array}{c}-0.0615 \\
{[0.101]}\end{array}$ & $\begin{array}{c}-0.0997^{*} \\
{\left[0.038^{+}\right]}\end{array}$ & $\begin{array}{c}-0.0193 \\
{[0.300]}\end{array}$ & $\begin{array}{c}-0.1204^{* * *} \\
{\left[0.000^{+++}\right]}\end{array}$ & \\
\hline Months since last attended church & $\begin{array}{c}0.0003 \\
{[0.503]}\end{array}$ & $\begin{array}{c}-0.0056 \\
{[0.389]}\end{array}$ & $\begin{array}{l}0.0134 \\
{[0.734]}\end{array}$ & $\begin{array}{c}0.0142 \\
{[0.666]}\end{array}$ & $\begin{array}{c}0.0677^{* *} \\
{[0.926]}\end{array}$ & $\begin{array}{c}-0.0454^{*} \\
{\left[0.000^{+++}\right]}\end{array}$ & \\
\hline Does not attend church & $\begin{array}{l}0.0503 \\
{[0.673]}\end{array}$ & $\begin{array}{c}-0.0504 \\
{[0.270]}\end{array}$ & $\begin{array}{c}0.2437^{* *} \\
{\left[0.994^{++}\right]}\end{array}$ & $\begin{array}{l}0.1069 \\
{[0.826]}\end{array}$ & $\begin{array}{l}0.0271 \\
{[0.670]}\end{array}$ & $\begin{array}{c}-0.0269 \\
{[0.366]}\end{array}$ & \\
\hline Attend largest church & $\begin{array}{c}-0.0782^{*} \\
{\left[0.045^{+}\right]}\end{array}$ & $\begin{array}{c}-0.0051 \\
{[0.463]}\end{array}$ & $\begin{array}{c}-0.0781^{*} \\
{\left[0.035^{+}\right]}\end{array}$ & $\begin{array}{c}-0.0333 \\
{[0.250]}\end{array}$ & $\begin{array}{c}-0.0296 \\
{[0.171]}\end{array}$ & $\begin{array}{c}0.0555 \\
{\left[0.953^{+}\right]}\end{array}$ & \\
\hline Observations & 397 & 307 & 397 & 397 & 307 & 864 & 41 \\
\hline
\end{tabular}

Notes: Significance levels based on sampling-based inference with clustered standard errors indicated by ${ }^{*},{ }^{* *}$, and ${ }^{* * *}$ for $0.10,0.05$, and 0.01 levels respectively. Randomization-based $p$-value using 5000 draws appears in square brackets beneath. ${ }^{+}: p<0.05$ or $p>0.95,{ }^{++}$: $p<0.025$ or $p>0.975$, and ${ }^{+++}: p<0.005$ or $p>0.995$. 
Table A.3: Randomized vs Sampling Inference using Karlan (2005) Table 3

\begin{tabular}{|c|c|c|c|c|c|c|c|}
\hline \multirow{4}{*}{ Independent variables: } & \multicolumn{5}{|c|}{ Trust Game } & \multirow{2}{*}{\multicolumn{2}{|c|}{$\begin{array}{l}\text { Public Goods Game } \\
\text { Player characteristics }\end{array}$}} \\
\hline & \multicolumn{2}{|c|}{ Player characteristics } & \multicolumn{3}{|c|}{ Partner Characteristics } & & \\
\hline & $\begin{array}{c}\text { Proportion } \\
\text { passed } \\
\text { (Player A) }\end{array}$ & $\begin{array}{c}\text { Proportion } \\
\text { returned } \\
\text { (Player B) }\end{array}$ & $\begin{array}{l}\text { Proportion } \\
\text { passed } \\
\text { (Player A) }\end{array}$ & $\begin{array}{c}\text { Passed }>0 \\
(\text { Player A) }\end{array}$ & $\begin{array}{l}\text { Proportion } \\
\text { returned } \\
\text { (Player B) }\end{array}$ & $\begin{array}{c}\text { Binary }=1 \text { if } \\
\text { individual } \\
\text { contributed }\end{array}$ & $\begin{array}{l}\text { Proportion of } \\
\text { group that } \\
\text { contributed }\end{array}$ \\
\hline & $(1)$ & $(2)$ & $(3)$ & $(4)$ & $(5)$ & $(6)$ & $(7)$ \\
\hline \multicolumn{8}{|l|}{ Attitudinal/behavioral measures } \\
\hline Proportion passed in the Trust Game & & & & & & $\begin{array}{c}0.1159^{* *} \\
{[0.970]^{+}}\end{array}$ & $\begin{array}{c}0.1938 \\
{[0.995]^{+++}}\end{array}$ \\
\hline Amount received from Player A & & $\begin{array}{c}-0.0056 \\
{[0.938]}\end{array}$ & & & & & \\
\hline Sum of 3 GSS Questions, relative to group & $\begin{array}{c}-0.0103 \\
{[0.375]}\end{array}$ & $\begin{array}{l}0.0221 \\
{[0.858]}\end{array}$ & $\begin{array}{c}-0.0052 \\
{[0.400]}\end{array}$ & $\begin{array}{c}-0.0136 \\
{[0.292]}\end{array}$ & $\begin{array}{l}0.0049 \\
{[0.517]}\end{array}$ & $\begin{array}{l}0.0183 \\
{[0.895]}\end{array}$ & \\
\hline Sum of 3 GSS Questions, relative to society & $\begin{array}{c}-0.0006 \\
{[0.500]}\end{array}$ & $\begin{array}{c}0.0383^{*} \\
{[0.925]}\end{array}$ & $\begin{array}{c}-0.0206 \\
{[0.217]}\end{array}$ & $\begin{array}{c}-0.0237 \\
{[0.225]}\end{array}$ & $\begin{array}{l}0.0009 \\
{[0.532]}\end{array}$ & $\begin{array}{c}-0.0142 \\
{[0.247]}\end{array}$ & \\
\hline Sum of 6 GSS Questions for Entire Group & & & & & & & $\begin{array}{c}0.1210^{* *} \\
{[0.998]^{+++}}\end{array}$ \\
\hline Did not maximize available debt (savings > borrowing) & $\begin{array}{c}-0.0953^{* * *} \\
{[0.040]^{+}}\end{array}$ & $\begin{array}{l}0.0184 \\
{[0.647]}\end{array}$ & $\begin{array}{l}0.0928^{*} \\
{[0.963]^{+}}\end{array}$ & $\begin{array}{l}0.0383 \\
{[0.740]}\end{array}$ & $\begin{array}{l}0.0479 \\
{[0.792]}\end{array}$ & $\begin{array}{l}-0.0765 \\
{[0.045]^{+}}\end{array}$ & $\begin{array}{c}-0.0026 \\
{[0.477]}\end{array}$ \\
\hline \multicolumn{8}{|l|}{ Connectedness to group } \\
\hline Proportion of group of similar culture & $\begin{array}{l}0.0989 \\
{[0.725]}\end{array}$ & $\begin{array}{c}-0.2120 \\
{[0.092]}\end{array}$ & $\begin{array}{l}0.2799^{*} \\
{[0.958]^{+}}\end{array}$ & $\begin{array}{l}0.4058^{*} \\
{[0.988]^{++}}\end{array}$ & $\begin{array}{l}0.1765 \\
{[0.890]}\end{array}$ & $\begin{array}{l}0.0914 \\
{[0.855]}\end{array}$ & $\begin{array}{c}0.0684 \\
{[0.637]}\end{array}$ \\
\hline Distance to others in group & $\begin{array}{l}0.1163 \\
{[0.725]}\end{array}$ & $\begin{array}{c}-0.1478^{* *} \\
{[0.070]}\end{array}$ & $\begin{array}{c}-0.0344 \\
{[0.388]}\end{array}$ & $\begin{array}{l}0.0456 \\
{[0.650]}\end{array}$ & $\begin{array}{l}0.4130^{* * *} \\
{[0.998]^{+++}}\end{array}$ & $\begin{array}{l}-0.1896^{*} \\
{[0.000]^{+++}}\end{array}$ & $\begin{array}{l}0.0783 \\
{[0.750]}\end{array}$ \\
\hline Proportion of others who live within 10-minute walk & $\begin{array}{c}-0.0881 \\
{[0.247]}\end{array}$ & $\begin{array}{l}0.0588 \\
{[0.677]}\end{array}$ & $\begin{array}{c}-0.1149 \\
{[0.185]}\end{array}$ & $\begin{array}{c}-0.0102 \\
{[0.490]}\end{array}$ & $\begin{array}{c}0.1434 \\
{[0.895]}\end{array}$ & $\begin{array}{c}-0.0613 \\
{[0.168]}\end{array}$ & \\
\hline Instances borrowing from group member in side-contract & $\begin{array}{c}-0.0412^{*} \\
{[0.060]}\end{array}$ & $\begin{array}{c}0.0170^{* *} \\
{[0.938]}\end{array}$ & $\begin{array}{l}0.003 \\
{[0.563]}\end{array}$ & $\begin{array}{c}0.0143^{*} \\
{[0.815]}\end{array}$ & $\begin{array}{c}-0.0074 \\
{[0.357]}\end{array}$ & $\begin{array}{c}0.0088^{*} \\
{[0.715]}\end{array}$ & \\
\hline Number of other members able to name from memory & $\begin{array}{l}0.0006 \\
{[0.568]}\end{array}$ & $\begin{array}{c}-0.0016 \\
{[0.345]}\end{array}$ & $\begin{array}{c}-0.0016 \\
{[0.378]}\end{array}$ & $\begin{array}{c}-0.0075 \\
{[0.085]}\end{array}$ & $\begin{array}{c}-0.0034 \\
{[0.163]}\end{array}$ & $\begin{array}{l}0.0017 \\
{[0.672]}\end{array}$ & \\
\hline \multicolumn{8}{|l|}{ Connectedness to partner } \\
\hline Partner in same lending/saving group & $\begin{array}{c}-0.0443 \\
{[0.158]}\end{array}$ & $\begin{array}{l}0.0763 \\
{[0.965]^{+}}\end{array}$ & & & & & \\
\hline Both partners indigenous & $\begin{array}{c}0.2439^{* * *} \\
{[0.988]^{++}}\end{array}$ & $\begin{array}{l}0.0406 \\
{[0.665]}\end{array}$ & & & & & \\
\hline Both players western & $\begin{array}{l}0.0522 \\
{[0.805]}\end{array}$ & $\begin{array}{c}-0.0121 \\
{[0.438]}\end{array}$ & & & & & \\
\hline Player Western; partner indigenous & $\begin{array}{l}-0.055 \\
{[0.285]}\end{array}$ & $\begin{array}{c}0.1766^{* * *} \\
{[0.983]^{++}}\end{array}$ & & & & & \\
\hline Player indigenous; partner Western & $\begin{array}{l}0.1241 \\
{[0.875]}\end{array}$ & $\begin{array}{c}-0.0200 \\
{[0.420]}\end{array}$ & & & & & \\
\hline Partner lives within 10-minute walk & $\begin{array}{c}0.0901^{* *} \\
{[0.950]^{+}}\end{array}$ & $\begin{array}{l}0.0555 \\
{[0.895]}\end{array}$ & & & & & \\
\hline Attends same small church as partner & $\begin{array}{c}0.1993^{* *} \\
{[0.950]^{+}}\end{array}$ & $\begin{array}{l}0.0450 \\
{[0.680]}\end{array}$ & & & & & \\
\hline Knew partner and her name & $\begin{array}{l}0.0444 \\
{[0.900]}\end{array}$ & $\begin{array}{c}-0.0049 \\
{[0.412]}\end{array}$ & & & & & \\
\hline Attended/Invited partner to party & $\begin{array}{l}0.0636 \\
{[0.667]}\end{array}$ & $\begin{array}{c}-0.0273 \\
{[0.407]}\end{array}$ & & & & & \\
\hline Absolute value of age difference & $\begin{array}{l}0.0009 \\
{[0.695]}\end{array}$ & $\begin{array}{l}0.0004 \\
{[0.615]}\end{array}$ & & & & & \\
\hline \multicolumn{8}{|l|}{ Demographic information } \\
\hline Completed high school & $\begin{array}{l}0.1221^{* *} \\
{[0.975]^{++}}\end{array}$ & $\begin{array}{l}0.0521 \\
{[0.897]}\end{array}$ & $\begin{array}{l}0.0408 \\
{[0.782]}\end{array}$ & $\begin{array}{l}0.0802 \\
{[0.877]}\end{array}$ & $\begin{array}{c}0.0759 \\
{[0.978]^{++}}\end{array}$ & $\begin{array}{c}-0.0339 \\
{[0.107]}\end{array}$ & \\
\hline $\ln ($ age $)$ & $\begin{array}{l}0.1055^{* *} \\
{[0.998]^{+++}}\end{array}$ & $\begin{array}{c}0.0782 \\
{[0.983]^{++}}\end{array}$ & $\begin{array}{c}-0.0404 \\
{[0.177]}\end{array}$ & $\begin{array}{c}-0.0262 \\
{[0.305]}\end{array}$ & $\begin{array}{c}0.0549^{*} \\
{[0.917]}\end{array}$ & $\begin{array}{l}-0.0615 \\
{[0.045]^{+}}\end{array}$ & \\
\hline Indigenous & $\begin{array}{c}-0.0741 \\
{[0.182]}\end{array}$ & $\begin{array}{l}0.0292 \\
{[0.693]}\end{array}$ & $\begin{array}{l}0.0869^{*} \\
{[0.953]^{+}}\end{array}$ & $\begin{array}{l}0.0824 \\
{[0.905]}\end{array}$ & $\begin{array}{l}0.0912^{*} \\
{[0.970]^{+}}\end{array}$ & $\begin{array}{c}-0.0031 \\
{[0.497]}\end{array}$ & \\
\hline Western & $\begin{array}{c}-0.0017 \\
{[0.470]}\end{array}$ & $\begin{array}{l}0.0789 \\
{[0.897]}\end{array}$ & $\begin{array}{c}-0.0615 \\
{[0.092]}\end{array}$ & $\begin{array}{c}-0.0997^{*} \\
{[0.040]^{+}}\end{array}$ & $\begin{array}{c}-0.0193 \\
{[0.313]}\end{array}$ & $\begin{array}{c}-0.1204^{* * *} \\
{[0.000]^{+++}}\end{array}$ & \\
\hline Months since last attended church & $\begin{array}{l}0.0003 \\
{[0.507]}\end{array}$ & $\begin{array}{c}-0.0056 \\
{[0.445]}\end{array}$ & $\begin{array}{c}0.0134 \\
{[0.725]}\end{array}$ & $\begin{array}{c}0.0142 \\
{[0.647]}\end{array}$ & $\begin{array}{c}0.0677^{* *} \\
{[0.910]}\end{array}$ & $\begin{array}{c}-0.0454^{*} \\
{[0.000]^{+++}}\end{array}$ & \\
\hline Does not attend church & $\begin{array}{l}0.0503 \\
{[0.667]}\end{array}$ & $\begin{array}{c}-0.0504 \\
{[0.285]}\end{array}$ & $\begin{array}{l}0.2437^{* *} \\
{[0.995]^{+++}}\end{array}$ & $\begin{array}{l}0.1069 \\
{[0.853]}\end{array}$ & $\begin{array}{l}0.0271 \\
{[0.677]}\end{array}$ & $\begin{array}{c}-0.0269 \\
{[0.417]}\end{array}$ & \\
\hline Attend largest church & $\begin{array}{c}-0.0782^{*} \\
{[0.043]^{+}}\end{array}$ & $\begin{array}{c}-0.0051 \\
{[0.495]}\end{array}$ & $\begin{array}{c}-0.0781^{*} \\
{[0.043]^{+}}\end{array}$ & $\begin{array}{c}-0.0333 \\
{[0.268]}\end{array}$ & $\begin{array}{c}-0.0296 \\
{[0.185]}\end{array}$ & $\begin{array}{c}0.0555 \\
{[0.960]^{+}}\end{array}$ & \\
\hline Observations & 397 & 307 & 397 & 397 & 307 & 864 & 41 \\
\hline
\end{tabular}

Notes: Repetition of Table 19 using random seed which produces large number of observations in the left tail. Significance levels based on sampling-based inference with clustered standard errors indicated by $*, * *$, and $* * *$ for $0.10,0.05$, and 0.01 levels respectively. Randomization-based $p$-value using 400 draws appears in square brackets beneath. ${ }^{+}: p<0.05$ or $p>0.95,{ }^{++}: p<0.025$ or $p>0.975$, and ${ }^{+++}: p<0.005$ or $p>0.995$. 